\title{
Mental Health of Refugee and Non-refugee Migrant Young People in European Secondary Education: The Role of Family Separation, Daily Material Stress and Perceived Discrimination in Resettlement
}

\author{
Caroline Spaas $\mathbb{B}^{1} \cdot$ An Verelst $^{2} \cdot$ Ines Devlieger ${ }^{3} \cdot$ Sanni Aalto ${ }^{4} \cdot$ Arnfinn J. Andersen $^{5} \cdot$ Natalie Durbeej $^{6}$. \\ Per Kristian Hilden ${ }^{5}$. Reeta Kankaanpää ${ }^{4}$. Nina Langer Primdahl ${ }^{7} \cdot$ Marianne Opaas $^{5} \cdot$ Fatumo Osman $^{6}$. \\ Kirsi Peltonen ${ }^{4} \cdot$ Anna Sarkadi $^{6} \cdot$ Morten Skovdal $^{7} \cdot$ Signe Smith Jervelund ${ }^{7} \cdot$ Emma Soye $^{8} \cdot$ Charles Watters $^{8}$. \\ Ilse Derluyn ${ }^{2} \cdot$ Hilde Colpin $^{9} \cdot$ Lucia De Haene $^{1}$
}

Received: 27 May 2021 / Accepted: 12 September 2021

(c) The Author(s), under exclusive licence to Springer Science+Business Media, LLC, part of Springer Nature 2021

\begin{abstract}
While scholarly literature indicates that both refugee and non-refugee migrant young people display increased levels of psychosocial vulnerability, studies comparing the mental health of the two groups remain scarce. This study aims to further the existing evidence by examining refugee and non-refugee migrants' mental health, in relation to their migration history and resettlement conditions. The mental health of 883 refugee and 483 non-refugee migrants (mean age 15.41, range 11-24, $45.9 \%$ girls, average length of stay in the host country 3.75 years) in five European countries was studied in their relation to family separation, daily material stress and perceived discrimination in resettlement. All participants reported high levels of post-traumatic stress symptoms. Family separation predicted post-trauma and internalizing behavioral difficulties only in refugees. Daily material stress related to lower levels of overall well-being in all participants, and higher levels of internalizing and externalizing behavioral difficulties in refugees. Perceived discrimination was associated with increased levels of mental health problems for refugees and non-refugee migrants. The relationship between perceived discrimination and post-traumatic stress symptoms in non-refugee migrants, together with the high levels of post-traumatic stress symptoms in this subsample, raises important questions on the nature of trauma exposure in non-refugee migrants, as well as the ways in which experiences of discrimination may interact with other traumatic stressors in predicting mental health.
\end{abstract}

Keywords Refugee youth and adolescents $\cdot$ Migrant youth and adolescents $\cdot$ Mental health $\cdot$ Family separation $\cdot$ Daily material stress $\cdot$ Discrimination

Caroline Spaas

caroline.spaas@kuleuven.be

1 Parenting and Special Education Research Unit, Faculty of Psychology and Educational Sciences, University of Leuven, Leuven, Belgium

2 Centre for the Social Study of Migration and Refugees, Department of Social Work and Social Pedagogy, Ghent University, Ghent, Belgium

3 Department of Data Analysis, Faculty of Psychology and Educational Sciences, Ghent University, Ghent, Belgium

4 Faculty of Social Sciences/Psychology, Tampere University, Tampere, Finland
5 Norwegian Centre for Violence and Traumatic Stress Studies, NKVTS, Oslo, Norway

6 Child Health and Parenting (CHAP), Department of Public Health and Caring Sciences, Uppsala University, Uppsala, Sweden

7 Department of Public Health, University of Copenhagen, Copenhagen, Denmark

8 School of Education and Social Work, University of Sussex, Brighton, UK

9 School Psychology and Development in Context Research Unit, Faculty of Psychology and Educational Sciences, University of Leuven, Leuven, Belgium 


\section{Introduction}

In 2019, 272 million people worldwide resided in a country other than their country of birth, about 38 million of them were children (International Organization of Migration, 2019). In 2020, 26.4 million refugees were forcibly displaced outside their home countries, in pursuit of safety from war, conflict and persecution (UNHCR, 2021). Minors make up 42 percent of the forcibly displaced population worldwide (UNHCR, 2021). In 2019, migrants and refugees represented 11 percent of Europe's total population (International Organization of Migration, 2019). This diversity raises the issue of how best to support refugee and migrant children and adolescents in their development and adaptation in resettlement (Reed et al., 2012). Indeed, gaining an accurate understanding of their mental health has become a pertinent public health concern across European host societies (Tedros, 2019). Recent scholarly reviews emphasize a present-day lack of sufficiently powered studies on this matter (e.g., Kien et al., 2018). Also, while scholarly literature that is available generally indicates that both refugee children and adolescents, forcibly displaced due to war, conflict or prosecution (United Nations, 2021), as well as their non-refugee migrant peers, migrating for different reasons (e.g., economic, work reasons), display increased levels of psychosocial vulnerability, studies comparing the mental health of the two groups remain scarce. This study therefore aims to further the existing evidence by examining the mental health of 883 refugee and 483 non-refugee migrant adolescents and youth (age 11 to 24, mean age 15.41 , referred to in this manuscript as "young people", consistent with the umbrella term proposed by the World Health Organization to capture adolescence (age 10-19) and youth (age 15-24) (World Health Organization, 2014)). The study examines refugee and non-refugee migrant young people's mental health in relation to family separation, daily material stress and discrimination in resettlement.

\section{Refugee and Non-refugee Migrant Young People's Development and Mental Health}

Refugee and non-refugee migrant young people face the complexity of performing developmental tasks in a multiethnic environment, and in interaction with acculturative tasks, experiencing social and cultural uprooting and loss as well as particular minority- and resettlement-related stressors (Pacione et al., 2013). Many of these young people experience material strain in resettlement. In 2018, 33\% of young refugee and non-refugee migrants born in other EU member states and $44 \%$ of those born outside the EU were at risk of poverty or material deprivation, compared to $25 \%$ of native-born young people (Eurostat, 2019). In addition, refugee and non-refugee migrant young people's educational trajectories are often shattered in their home country or underway (McDonald et al., 2017). Their school trajectories in resettlement can remain at risk, characterized by inadequate psychosocial support, the detrimental effect of discrimination on mental health, unstable school attendance, significant drop-out rates, high levels of grade repetition and inadequate orientation (UNHCR et al., 2019, Walker \& Zuberi, 2020).

Whereas studies testify to refugee and non-refugee migrants' resilience and the complex but unique value of hybrid identity development (e.g., Pieloch et al., 2016), research also emphasizes how material stressors in resettlement, compounded by language and academic barriers, acculturation challenges, uprooting and social isolation, may complicate their adaptation, development, and negatively impact their mental health (e.g., Miller \& Rasmussen, 2017; Shakya et al., 2010). Moreover, within the climate of fear and distrust towards migrants that characterizes increasingly polarized Western host societies, experiences of exclusion and discrimination may exacerbate these adaptation challenges and negative mental health sequelae (e.g., da Silva Rebelo et al., 2018). Experiences of discrimination have previously been shown to complicate school adjustment (Bayram Özdemir \& Stattin, 2014) and young people's adaptation in resettlement (Buchanan et al., 2018), and to be related to a range of internalizing mental health difficulties (e.g., Beiser \& Hou, 2016), such as anxiety, depression, low (academic) self-esteem (Hassan et al., 2013) and young people's sense of social competence in peer relations (Oxman-Martinez et al., 2012). In sum, recent systematic review studies conclude that being a migrant in Europe appears to constitute a risk factor for adjustment and mental health, particularly so for the development of internalizing mental health problems (Dimitrova et al., 2016; Kouider et al., 2014).

\section{Complex and Clustered Stressors Characterize the Lives of Refugee Young People}

For refugees, resettlement-related stressors of material stress or deprivation, cultural uprooting, social isolation and discrimination most often follow prior traumatic experiences in refugees' home country, and on their journeys to Europe. Traumatic experiences may include exposure to violent conflict and prolonged threat, human rights violations, forced separation from parents or caregivers, detention and experiences of torture. These have previously been related to poorer psychosocial integration and negative mental health outcomes (e.g., Hodes \& Vostanis, 2019). The impact of post-flight stressors may continue or aggravate the adverse effect of previous trauma, resulting in life-trajectories of forced displacement marked by cumulative, and often pervasive psychological distress in which post-migration stressors reactivate 
traumatic suffering (De Haene \& Rousseau, 2020b). Studies consistently reveal how this complex cluster of migrationrelated stressors may constrain refugee children and young people's development and put them at an increased risk for a broad range of psychosocial and mental health difficulties, with high prevalence rates of anxiety, depression, posttraumatic stress disorder (PTSD) (e.g., Pacione et al., 2013), behavioral and academic problems (e.g., Betancourt et al., 2012). Recent research with refugee children and adolescents situates prevalence rates between 19 and $52.7 \%$ for PTSD, between 10.3 and $32.8 \%$ for depression, between 8.7 and $31.6 \%$ for anxiety, and between 19.8 and $35 \%$ for emotional and behavioral problems (Kien et al., 2018).

\section{Non-refugee Migrant Young People: An Equally Vulnerable Group?}

From the existing evidence-base, it is clear that both refugee and non-refugee migrant young people display increased levels of psychosocial vulnerability. While the impact of post-migration stressors of material deprivation, cultural uprooting, social exclusion and discrimination on mental health may be shared by both refugee and nonrefugee migrants, it remains largely unclear if young people migrating for reasons other than war and collective violence in their home countries, should be considered equally vulnerable in terms of their mental health as their refugee counterparts. Studies comparing the mental health of both groups are scarce. Some suggest that precisely the recurrence and pervasiveness of traumatic lifeexperiences distinguish refugees from their non-refugee migrant peers, emphasizing higher levels of premigration trauma in refugees, a higher total exposure to more diverse traumatic experiences, as well as the complex interplay between different traumatic experiences across refugee life spans (Beiser \& Hou, 2016; Betancourt et al., 2017). In contrast, a handful of studies indicate similarities in exposure to violence in both refugee and nonrefugee migrant children and young people. A U.S. study provided the first empirical evidence on high rates of violence exposure as well as increased levels of PTSD and depressive symptoms in non-refugee migrant school children, indicating the influence of previous traumatic stressors in children's home countries (e.g., crime), as well as domestic and community violence in resettlement (Jaycox et al., 2002). Equally, a European study documented high levels of PTSD in both refugee and nonrefugee children (Kevers et al., 2021). Given the increasingly harsh European border policies, authors also suspect analogous exposure to experiences of traumatic hardship during the migration trajectory, including family separation, (sexual) exploitation, and detention (e.g., Derluyn et al., 2009). Additionally, migration-related separation from family members in both refugee and nonrefugee migrant children and young people may impact mental health, as findings indicate the predictive role of separation in increasing academic difficulties (Grindling \& Poggio, 2012), levels of daily stress in resettlement (Keles, 2016) and the risk of psychopathology in both groups (Derluyn et al., 2008; Miller et al., 2018).

\section{Current Study}

Gaining an accurate understanding of refugee and nonrefugee migrant young people's mental health has become a pertinent public health concern across European host societies, but sufficiently powered studies on this matter are still lacking. Furthermore, while the body of scholarly literature that exists indicates that both refugee and non-refugee migrant young people display increased levels of psychosocial vulnerability, studies comparing the mental health of the two groups remain scarce. This study therefore engages in a comparison of mental health in a large sample of 883 refugee and 483 non-refugee migrant young people in 83 European schools. The study examines post-traumatic stress symptoms, externalizing and internalizing behavioral difficulties and overall well-being, and looks at the role of family separation, daily material stress and perceived discrimination in refugee and non-refugee migrants' mental health. Based on prior studies underscoring the impact of migration-related stressors, social and cultural uprooting on adolescent mental health, the study hypothesizes considerable mental health difficulties in both refugee and non-refugee migrant young people (Hypothesis 1). Given the pervasiveness of refugees' traumatic life-experiences and the complex cumulation and interaction between different traumatic experiences across refugee life spans, it is hypothesized that refugees suffer higher levels of mental health difficulties than non-refugee migrants (Hypothesis 2). The study also hypothesizes the negative impact of family separation, daily material stress and perceived discrimination on mental health to be greater in refugees than non-refugee migrants, again because of the complex and intersecting traumas characterizing their life histories (Hypothesis 3).

\section{Method}

\section{Study Setting and Participants}

This study results from a larger research project investigating the effectiveness of psychosocial interventions for refugee and migrant young people in secondary schools in five European countries (RefugeesWellSchool (RWS), a European Horizon 2020 study). The present study uses the 
baseline data on mental health, daily stress and perceived discrimination collected within the RWS study.

Purposive recruitment of schools in all five countries occurred between January 2018 and October 2019. Incountry timing of recruitment corresponded to the timeline underlying the national implementation of the RWS intervention study. In all participating countries, schools with large numbers of refugee and non-refugee migrants were targeted. These schools received information about the project and were invited to participate. Depending on the characteristics of the national education system, schools were contacted either directly by the research team (Finland, Sweden) or informed about the project via overarching, municipal and national departments of education (Belgium, Denmark, Norway). Eventually, 83 schools were selected to participate (Belgium: $n=10$; Denmark: $n=27$; Finland: $n=16$; Norway: $n=21$; Sweden: $n=9$ ). In all countries, this final selection was based primarily on schools' interest to participate in the RWS study and the number of refugee and non-refugee migrants in the school. In Belgium and Norway, the geographical location of schools formed an added selection criterion, i.e., schools were selected within comparable urban settings, as to aspire homogeneity in participants' environments, as well as feasible data collection and intervention implementation.

Recruitment of participants for the study took place in a total of 290 classes. In each country, classes were selected in accordance with the target group of the different interventions under study nationally. Criteria were for example class group size or students' host country language proficiency (e.g., understanding of basic instructions as to be able to engage in an intervention group activity). In Norway, young people illiterate in their mother tongue and the host country language were excluded, because of limited possibilities of using interpreters during recruitment and assessment. Within each country, young people were informed about the project in class, during school hours. In Denmark this information was provided by young people's teachers, instructed beforehand by the research team. In the other countries, members of the research team were themselves present in class to introduce the project and work alongside teachers in obtaining young people's informed consent. Corresponding to ethical guidelines for gaining access to and establishing trustful research relationships with refugee communities (de Smet et al., 2021), all national research teams provided young people with a tailored and exhaustive explanation of the project, using information sheets in their mother tongue and visual support in the form of a PowerPoint-presentation containing images explaining the main aspects of the project. In Belgium and Norway, interpreters were present during the information sessions when needed. In accordance with ethical guidelines on informed consent procedures with minors, additional consent of parents was sought out for young people below the nationally defined age for individual consent. Older participants were deemed eligible to decide on their own participation and were given a complementary letter for their parents only if they felt the need to check their participation with their parents. These participants were assured they could withdraw from the study in case their parents did not agree to their participation.

A total of 1366 young people (mean age $=15.41$ years) were recruited across the five participating countries. In Table 1, demographic characteristics of the total group of participants and of refugee versus non-refugee migrant young people are summarized. Based on background information provided by participants through standardized questionnaires, they were categorized as refugees or nonrefugee migrants depending on their indicated migration motive (e.g., "war" or "persecution" versus "my parents came here for work"), as well as their country of origin (e.g., "Afghanistan", "Syria", "Somalia" versus "Poland", "Romania"). Asylum-seeking participants, awaiting a decision for international protection, as well as young people without legal documentation, were included as "refugees" in the sample. A total of 883 young people $(64.6 \%)$ were categorized as refugees and $483(35.4 \%)$ were categorized as non-refugee migrants. The participant sample was heterogeneous in terms of countries of origin, with participants originating from 98 countries. Refugee young people were born in 38 different countries, mainly in Syria $(n=241,27.3 \%)$, Somalia $(n=183,20.7 \%)$ and Afghani$\operatorname{stan}(n=149,16.9 \%)$. For non-refugee migrant young people countries of origin were even more diverse, 88 in total, with the largest subgroups born in Bulgaria $(n=51$, $10.6 \%)$, Thailand $(n=35,7.2 \%)$, Poland $(n=27,5.6 \%)$, Ghana $(n=26,5.4 \%)$, Romania $(n=23,4,8 \%)$ and Spain $(n=21,4.3 \%)$. Participants differed in terms of years spent in resettlement, the length of stay in their respective host country ranged from less than one to 21 years, with an average of 3.75 years $(S D=3.42)$.

\section{Measures and Procedure}

Data collection involved a baseline assessment of participants' mental health, daily material stress and perceived discrimination in resettlement through the administration of standardized questionnaires between January 2019 and March 2020. Timing of this baseline assessment again depended on the different in-country timelines underlying the implementation of the RWS intervention study. Assessment was organized in groups and took place in schools. Participants completed the questionnaire, which was translated and back-translated into 22 different languages, on paper (Belgium, Denmark) or online, using LimeSurvey (Denmark, Finland, Norway, Sweden) 
Table 1 Demographic characteristics (\%) of the participants

Total group Refugees Non-refugee migrants

\begin{tabular}{|c|c|c|c|}
\hline Gender & $N=1333$ & $N=859$ & $N=474$ \\
\hline Male & 54.1 & 55.9 & 50.8 \\
\hline Female & 45.9 & 44.1 & 49.2 \\
\hline Age & $N=1309$ & $N=844$ & $N=465$ \\
\hline 11 years & 1.1 & 0.9 & 1.5 \\
\hline 12 years & 3.5 & 3.0 & 4.5 \\
\hline 13 years & 11.8 & 9.5 & 16.1 \\
\hline 14 years & 16.9 & 15.6 & 19.1 \\
\hline 15 years & 20.9 & 18.7 & 24.9 \\
\hline 16 years & 19.2 & 20.1 & 17.4 \\
\hline 17 years & 15.5 & 17.7 & 11.6 \\
\hline 18 years & 6.0 & 7.1 & 4.1 \\
\hline 19 years & 2.1 & 3.2 & 0.0 \\
\hline 20 years & 0.7 & 0.8 & 0.4 \\
\hline 21 years & 0.3 & 0.4 & 0.2 \\
\hline 22 years & 0.8 & 1.2 & 0.0 \\
\hline 23 years & 0.8 & 1.2 & 0.0 \\
\hline 24 years & 0.4 & 0.6 & 0.0 \\
\hline Resettlement country & $N=1366$ & $N=883$ & $N=483$ \\
\hline Belgium & 38.8 & 23.1 & 15.7 \\
\hline Denmark & 19.0 & 13.0 & 6.0 \\
\hline Finland & 12.3 & 7.0 & 5.3 \\
\hline Norway & 16.5 & 10.4 & 6.1 \\
\hline Sweden & 13.4 & 11.1 & 2.3 \\
\hline Time in resettlement & $N=1280$ & $N=827$ & $N=453$ \\
\hline$<1$ year & 3.0 & 2.3 & 4.4 \\
\hline 1 years & 28.1 & 26.0 & 32.0 \\
\hline 2 years & 20.2 & 23.9 & 13.5 \\
\hline 3 years & 9.5 & 12.2 & 4.4 \\
\hline 4 years & 8.4 & 8.6 & 8.2 \\
\hline 5 years & 5.8 & 4.8 & 7.5 \\
\hline 6 years & 4.8 & 4.0 & 6.2 \\
\hline 7 years & 4.6 & 4.0 & 5.7 \\
\hline 8 years & 3.4 & 3.3 & 3.5 \\
\hline 9 years & 2.8 & 2.8 & 2.9 \\
\hline 10 years & 3.2 & 2.3 & 4.9 \\
\hline$>10$ years & 6.2 & 5.8 & 6.8 \\
\hline
\end{tabular}

(LimeSurvey Project Team/Carsten Schmitz, 2012). When needed, participants were assisted by the research teams or teachers. For participants with limited literacy in both their native language and the language of the host society, administration of the questionnaire was supported by translation by qualified interpreters in Belgium, Norway and Sweden. Although questionnaires were completed in the same classroom, participants completed the questionnaire independently. They were repeatedly informed that their answers would be treated confidentially in order to decrease socially desirable response tendencies. Additionally, participants were ensured that they could withdraw from study participation at any time during the assessment, without having to give an explanation (An overview of measures, their respective items and corresponding scoring is provided in Appendix A).

\section{Young people's mental health}

The following three measures informed analysis of young people's mental health.

Post-traumatic stress symptoms (PTSS) Participants were invited to complete the Children's Revised Impact of Events Scale-8 (CRIES-8; Perrin et al., 2005). The CRIES-8 is a brief self-report measure of symptoms of post-traumatic stress, developed for use with 8 to 18-year-old children and adolescents. The scale consists of four items questioning symptoms of intrusion and four items related to symptoms of avoidance. Each item is scored on a four-point Likert scale with $0=$ "not at all", $1=$ "rarely", $3=$ "sometimes" and $5=$ "often". The total score, i.e., the sum of all eight items and ranging between zero and 40, has previously shown good internal consistency and validity (e.g., Magalhães et al., 2018). Previous studies furthermore describe the use and value of the CRIES-8 as a screening tool for post-traumatic stress disorder (PTSD; American Psychiatric Association, 2013) in refugee children and adolescents (Salari et al., 2016; 2017).

Total, internalizing and externalizing behavioral difficulties All participants completed the Strengths \& Difficulties Questionnaire (SDQ; Goodman, 1997; 2001). The SDQ is a well-validated and widely used 25-item measure of emotional and behavioral difficulties in children and adolescents (Goodman et al., 2000). The SDQ has been extensively applied within culturally diverse study populations and has been translated in over 40 languages (Bourdon et al., 2005; Goodman, 2001). SDQ items have to be scored on a 3-point Likert scale with $0=$ "not true", $1=$ "somewhat true", and $2=$ "certainly true". Summing up their scores allows the researcher to compute a total mental health difficulties score (range 0-40), two broad subscale scores (internalizing and externalizing behavioral difficulties; range 0-20) and five smaller subscale scores (emotional problems, peer problems, behavioral problems, hyperactivity and prosocial behavior; range 0-10) (Goodman et al., 2010).

Overall well-being Participants answered one item on their overall well-being, namely "How would you rate your overall well-being", with the following answer and 
scoring options: "very bad" = 1, "bad" = 2, "normal" = 3 , "good" $=4$, "very good" $=5$.

\section{Family separation}

One item questioned if participants had experienced family separation. Specifically, it inquired if family separation occurred underway to the host country: "Were you ever separated from family members during your migration to this country?". Participants could answer this question "yes" or "no".

\section{Daily material stress}

Six items measuring daily material stressors were extracted from the Daily Stressors Scale for Young Refugees (DSSYR; Vervliet et al., unpublished) (Vervliet, M., Derluyn, I., \& Broekaert, E. (Unpublished). The Daily Stressors Scale for Young Refugees). The DSSYR was developed and previously used in the context of research into the mental health of unaccompanied refugee minors (Vervliet et al., 2014). The measure's items were based on the Columbia Impairment Scale (Bird et al., 1993), the Adolescents Complex Daily Stressors Scale (Mels et al., 2010), as well as the scientific knowledge of the researchers who developed the scale on the target population of unaccompanied refugees and their particular living circumstances. The instrument has not been validated to date, but has previously been used with refugee adolescents (e.g., Vervliet et al., 2014). In this study, the six selected items questioned to what extent during the last month participants had sufficient access to food, adequate clothing, money, necessary healthcare, a general feeling of security. All items were scored using a four-point Likert scale, with $1=$ "never", $2=$ "sometimes", 3= "often", 4= "always". Participants were furthermore granted the option not to answer the question if they did not know the answer to it or did not feel comfortable answering ("I don't know"/"I don't want to answer"). A mean score was computed, with a score range from 1 to 4 . Note that here, a lower mean score reflects a higher degree of daily material stress.

\section{Perceived discrimination}

Participants were asked to complete nine items corresponding to the exclusion and discrimination subscales of the Brief Perceived Ethnic Discrimination Questionnaire (PEDQ), measuring experiences of perceived ethnic discrimination within a social or interpersonal context. The total scale has been shown to possess good psychometric qualities and to be reliable when administered in culturally diverse and adolescent study populations (Brondolo et al., 2005). Items are scored on a four-point Likert scale, with $1=$ "never", 2 = "sometimes", 3 = "often" and 4 = "always". Participants could choose not to answer the question if they did not know the answer to it or did not feel comfortable answering ("I don't know"/"I don't want to answer"). A mean score was computed, with a scoring range from 1 to 4 .

\section{Analysis}

Statistical analyses were performed with SPSS 18 and R 4.0.3. To compare the mental health of refugee and nonrefugee migrants, multiple analyses were conducted. First, descriptive analyses of young people's responses were performed on two of the measures of mental health (PTSS, internalizing and externalizing behavioral difficulties). Analysis thereby examined reported levels of mental health symptomatology, both in the total sample and in a comparison between refugee and non-refugee migrant participants. Next, a multigroup structural equation model (SEM) was used to examine predictors of mental health, including the relation between family separation, daily material stress, perceived discrimination and mental health (PTSS, internalizing and behavioral difficulties, overall well-being). The multigroup SEM confirmed that the regressions in the model differed for refugees and nonrefugee migrants, $X^{2}(44)=66.316, p=0.016$. Therefore, the regressions are reported separately for both refugees and non-refugee migrants.

Previous to SEM-analyses a multigroup confirmatory factor analysis (CFA) was performed for each latent construct. The lavaan package version 0.6-8 (Rosseel, 2012) was used for this analysis, using the weighted least squares mean- and variance-adjusted (WLSMV) estimator. This implies that diagonally weighted least squares (DWLS) were used to estimate the model parameters and the full weight matrix was used to compute robust standard errors and a mean- and variance-adjusted test statistic. The goal of this multigroup CFA for each latent construct was two-fold. The first objective was to determine if the theorized measurement model showed an acceptable fit to the data. The fit of the model was assessed using several fit indices, i.e., the chi-square test statistic and p-value, Root Means Square Error of Approximation (RMSEA), Standardized Root Mean Square Residual (SRMR), Tucker-Lewis Index (TLI) and Comparative Fit Index (CFI). For the RMSEA a value below 0.06 is required for a good fit ( $\mathrm{Hu} \&$ Bentler, 1999) and a value below 0.08 indicates an acceptable fit (Schreiber et al., 2006). For the SRMR, Hu and Bentler (1999) recommended a value below 0.08. For CFI and TLI, values above 0.95 indicate a good fit, while values above 0.90 indicate an acceptable fit to the data (Brown, 2015; Browne \& Cudeck, 1993; Hu \& Bentler, 1999). If these fit indices were not adequate, the measurement models were 
adjusted based on the standardized factor loadings or on the modification indices. Possible adjustments were removal of certain indicators or adding correlations between error terms. These adjustments were systematically implemented one by one until a satisfactory model was found. Correlations between error terms were only added if they made theoretical sense. The second objective of the multigroup CFA was to determine measurement invariance between the two groups. This was to ensure that the differences in mental health found between the two groups did not stem from measurement differences across groups. To establish measurement invariance a configural baseline model where all parameters were estimated freely was compared to a model where the factor loadings were set to be equal across refugees and non-refugee migrants. If these models did not significantly differ from each other, weak measurement invariance was established. This model was then compared to a model where the intercepts, as well as the factor loadings were constrained to be equal across both groups. If these models did not differ significantly, strong measurement invariance was established. While some authors argue that establishing weak measurement invariance suffices to engage a comparison of mean differences (e.g., Vandenberg \& Morelli, 2016), the choice was made to also test for strong measurement invariance, since this is most cautious (e.g., Hirschfeld et al., 2014; Putnick \& Bronstein, 2016). If the baseline model did significantly differ with the second model, the modification indices were inspected to determine which items differed the most. These factor loadings were set free, while the invariant loadings were constrained to establish partial invariance (Byrne et al., 1989). The R-package semTools version 0.5-3.910 (Jorgensen et al., 2020) was used to assess measurement invariance for all latent scales. Also, Cronbach's alpha's and McDonald's omega reliability statistics were computed for the CRIES-8, SDQ internalizing and externalizing subscale, the DSSYR and PEDQ subscales, and are presented in Table 2.

Finally, the full multigroup structural equation model was fitted to the data using the lavaan package version 0.6-8 (Rosseel, 2012), again using the "WLSMV"-estimators. A simplified version of this model for refugees and nonrefugee migrants can be found in Figs. 1 and 2. Multiple imputation was performed, using the R-package mice, version 3.12 (van Buuren \& Groothuis-Oudshoorn, 2011), to deal with missing data. Over all measures, $5.5 \%$ of item scores were missing (Gender: $2.4 \%$; Age: $4.2 \%$; Family Separation: 6.1\%; Time in Country: 6.3\%, Overall Wellbeing: 3.9\%; CRIES-8: 5.0\%; SDQ: 3.9\%; DSSYR: 6.9\%; PEDQ: 11\%). Rubin's (1987) rules were used to pool point estimates and standard error estimates across five imputed data sets. The fit of the model to the data was evaluated, using the same fit indices as above.

\section{Measurement Invariance and Fit}

A configural baseline model underlay measurement invariance testing, assuming the measure's factor structure is the same across all groups in a multi-group confirmatory factor analysis. Weak or metric measurement invariance assumes the factor loadings of these configural models to be equivalent across groups. Strong or scalar measurement invariance assumes the same, but adds the constraint that also the intercepts of the items are equivalent across groups.

\section{PTSS}

For the CRIES-8 scale partial measurement invariance was obtained when setting Item 4 ("Do you stay away from reminders of it (e.g., places or situations)?") and 5 ("Do you try not talk about it?") were allowed to differ $(10.139, p=$ 0.071 ). This model showed a moderate model fit, TLI $=$ $0.988, \mathrm{CFI}=0.991, \mathrm{RMSEA}=0.088$ and $\mathrm{SRMR}=0.059$. Further inspection of the modification indices suggested allowing a correlation between Items 5 and 8 ("Do you try not talk about it?" and "Do you try not to think about it?"), between Items 6 and 7 ("Do pictures about it pop into your mind?" and "Do other things keep making you think about it?"), Items 1 and 3 ("Do you think about it even when you don't mean to?" and "Do you have waves of strong feelings about it?") and Items 7 and 8 (respectively: "Do other things keep making you think about it?" and "Do you try not to think about it?"). The modified model showed an acceptable fit, 259.96, $p=<0.001$, TLI $=0.991$, CFI $=$ 0.994, RMSEA $=0.077$ and SRMR $=0.0487$.

\section{Internalizing behavioral difficulties}

The internalizing SDQ-scale subscale showed partial measurement invariance $(11, p=0.51)$, when allowing Items 11 , 14,16 and 23 (respectively "I have one good friend or more", "Other people my age generally like me", "I am nervous in new situations. I easily lose confidence" and "I get on better with adults than with people my own age") to differ for refugees and non-refugee migrants. The modified model showed an acceptable fit, 201.28, $p=<0.001$, TLI $=0.941$, $\mathrm{CFI}=0.949, \mathrm{RMSEA}=0.058$ and $\mathrm{SRMR}=0.071$.

\section{Externalizing behavioral difficulties}

The externalizing SDQ-scale subscale showed weak measurement invariance $(15.631, p=0.075)$. This model showed a moderate model fit, TLI $=0.882, \mathrm{CFI}=0.908$, RMSEA $=0.069$ and SRMR $=0.085$. Further inspection of the modification indices suggested allowing a correlation between Items 21 and 25 (respectively "I think before I do things" and "I finish the work I'm doing. 
Table 2 Reliability statistics of scales

\begin{tabular}{lllll}
\hline & $\alpha$-Refugees & $\begin{array}{l}\alpha \text {-Non-refugee } \\
\text { migrants }\end{array}$ & $\Omega$-Refugees & $\begin{array}{l}\Omega \text {-Non-refugee } \\
\text { migrants }\end{array}$ \\
\hline CRIES-8 & 0.91 & 0.94 & 0.87 & 0.90 \\
$\begin{array}{l}\text { Externalizing behavioral } \\
\text { difficulties }\end{array}$ & 0.75 & 0.75 & 0.55 & 0.54 \\
$\begin{array}{l}\text { Internalizing behavioral } \\
\text { difficulties }\end{array}$ & 0.71 & 0.76 & 0.66 & 0.70 \\
$\begin{array}{l}\text { Daily material stress } \\
\text { Perceived discrimination }\end{array}$ & 0.91 & 0.92 & 0.85 & 0.87 \\
\hline
\end{tabular}

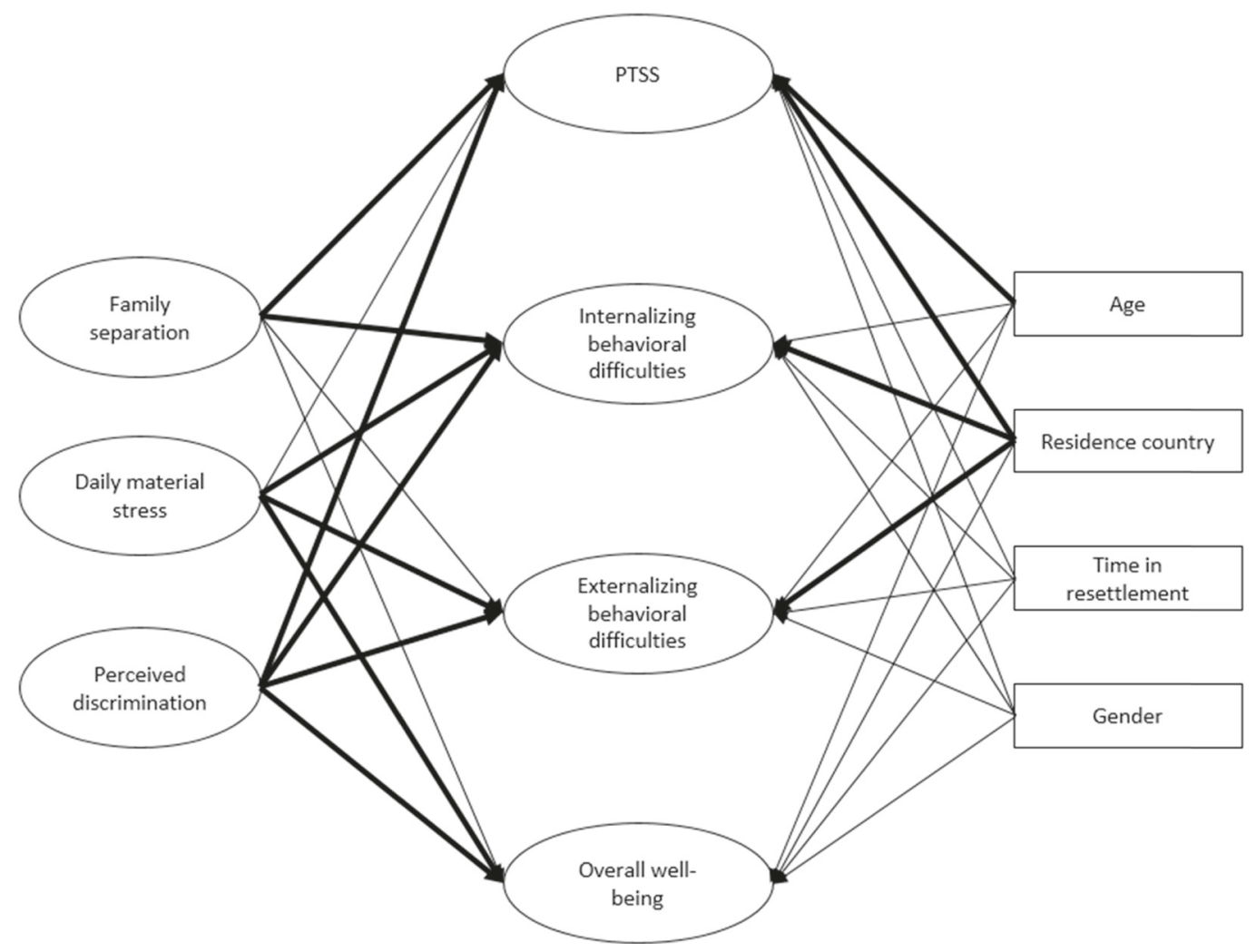

Fig. 1 Model relating age, residence country, time in resettlement, family separation, daily material stress and perceived discrimination to mental health measures for refugee participants in our sample. Note. For the sake of clarity, this figure is a simplified representation of the model, in which only the hypothesized relationships between variables are shown. The arrows in bold refer to statistically significant associations between variables in our analyses. The mutual correlations between endogenous variables in our model and the items underlying latent model variables are not pictured here

My attention is good"), between Items 7 and 25 (respectively "I usually do as I am told" and "I finish the work I'm doing. My attention is good") and items 2 and 10 (respectively "I am restless, I cannot stay still for long" and "I am constantly fidgeting or squirming"). The modified model showed a good fit, 107.58, $p=$ $<0.001, \mathrm{TLI}=0.973, \mathrm{CFI}=0.981, \mathrm{RMSEA}=0.033$ and $\mathrm{SRMR}=0.058$.

\section{Daily material stress}

The DDSYR-subscale showed weak measurement invariance (8.937, $p=0.112$ ). This model showed a good model fit, 520.79, $p=<0.001$, TLI $=0.995, \mathrm{CFI}=0.997$, $\mathrm{RMSEA}=0.058$ and SRMR $=0.048$.

\section{Perceived discrimination}

The PEDQ-subscales showed strong measurement invariance $(25.813, p=0.659)$. This model showed a moderate model fit, TLI $=0.963, \mathrm{CFI}=0.972, \mathrm{RMSEA}=0.079$ and SRMR $=0.087$. Further inspection of the modification indices suggested allowing a correlation between Items 1 and 6 (respectively "Have you been treated unfairly by principals or other staff at school?" and "Has your teacher been unfair to you?"), between Items 6 and 8 (respectively 


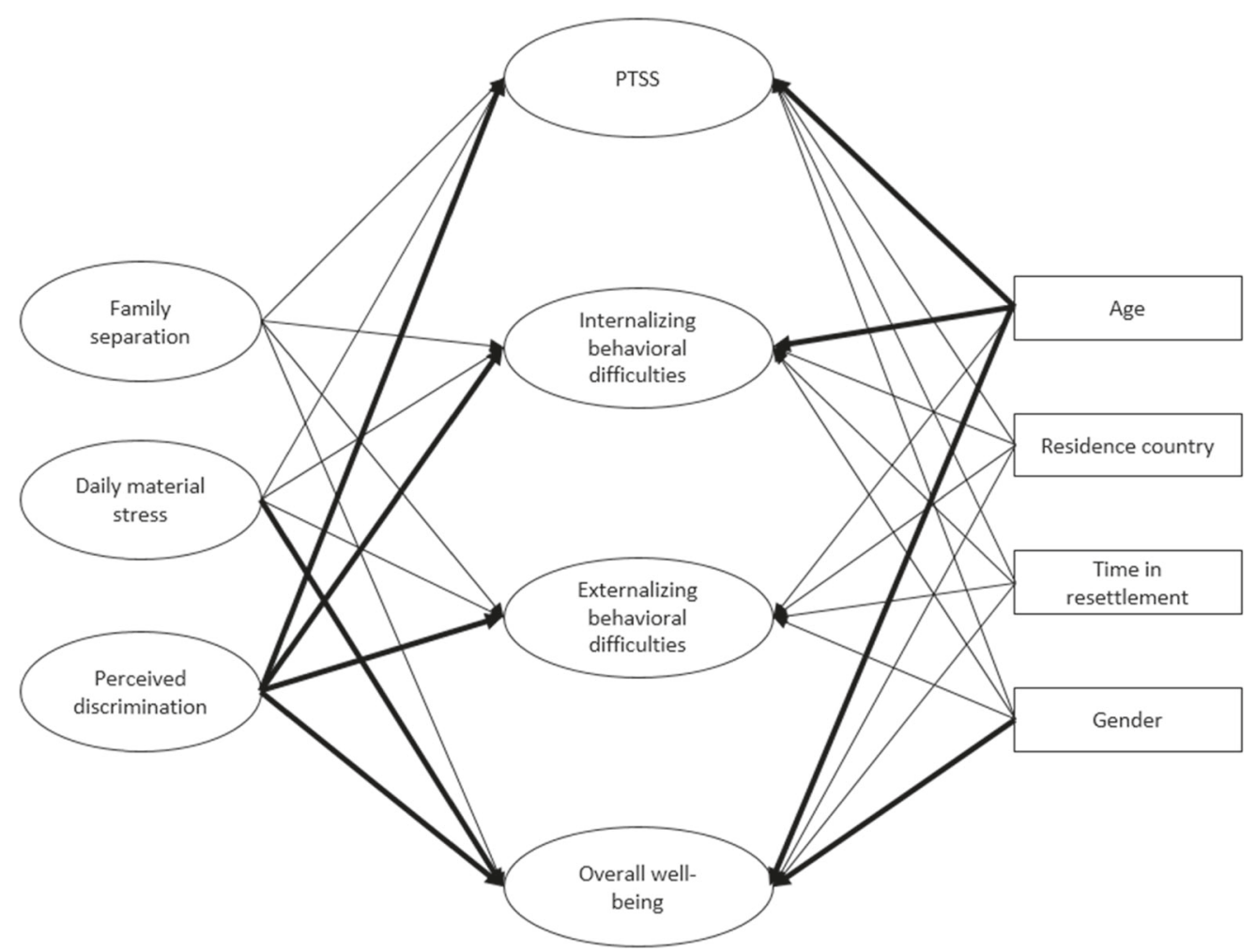

Fig. 2 Model relating age, residence country, time in resettlement, family separation, daily material stress and perceived discrimination to mental health measures for non-refugee migrant participants in our sample. Note. For the sake of clarity, this figure is a simplified representation of the model, in which only the hypothesized relationships between variables are shown. The arrows in bold refer to statistically significant associations between variables in our analyses. The mutual correlations between endogenous variables in our model and the items underlying latent model variables are not pictured here

"Has your teacher been unfair to you?" and "Has it been hinted that you must be lazy?"). The modified model showed a good fit, $120.88, p=<0.001, \mathrm{TLI}=0.982$, $\mathrm{CFI}=0.988, \mathrm{RMSEA}=0.054$ and $\mathrm{SRMR}=0.069$.

\section{Full multigroup SEM model}

The structural equation model that was used to compare the mental health of refugees and non-refugee migrants showed a good fit to the data, 5416.7, $p=<0.001$, TLI $=0.967$, $\mathrm{CFI}=0.956$, RMSEA $=0.041$ and $\mathrm{SRMR}=0.075$.

Further details on the performed measurement invariance tests and the fit indices of the final models are provided in Tables 3 and 4.

\section{Results}

\section{Refugee and Non-refugee Migrant Young People's Mental Health (Hypothesis 1 and 2)}

The means and standard deviations of all dependent variables measuring mental health are presented in Table 5. In order to reflect further on the clinical significance of these outcomes, participants' scores were categorized using cutoff scores employed in large population-based surveys. For PTSS the cut-off scores for clinical range were applied (Perrin et al., 2005). According to this classification, for participants completing all items of the CRIES-8, a sumscore above 17 corresponds to a clinical level of symptomatology, indicating a high probability of meeting the criteria for PTSD-diagnosis (American Psychiatric Association, 2013). For total, internalizing and externalizing behavioral difficulties, cut-offs were calculated based on the $90^{\text {th }}$ percentile of a large-scale British population survey (Youth in Mind, 2018). In order to optimize model fit, use of the SDQ internalizing and externalizing subscales was opted for in the SEM analyses. For these two subscales no cut-points for clinical categorization are available. However, the use of the five smaller subscales of the SDQ (emotional problems, peer problems, behavioral problems, hyperactivity and prosocial behavior) is recommended when researching high-risk samples (Goodman et al., 2010). A descriptive exploration of the clinical significance of participants' scores on these five subscales therefore complemented the analyses. Table 6 gives the clinical categorization (\%) of the entire sample and of refugee and nonrefugee migrant participants separately. 
Table 3 Measurement invariance test

\begin{tabular}{|c|c|c|c|c|c|c|c|c|c|c|}
\hline \multirow{2}{*}{$\overline{\text { CRIES-8 }}$} & \multirow[t]{2}{*}{$\chi^{2}$} & \multirow[t]{2}{*}{ Df } & \multirow[t]{2}{*}{$\mathrm{CFI}$} & \multirow[t]{2}{*}{ RMSEA } & \multicolumn{3}{|c|}{ Comparison } & \multirow[t]{2}{*}{$\Delta \chi^{2}$} & \multirow[t]{2}{*}{$\Delta \mathrm{df}$} & \multirow[t]{2}{*}{$p$} \\
\hline & & & & & & & & & & \\
\hline Configural invariance (Model 1) & 246.88 & 40 & 0.97 & 0.13 & & & & & & \\
\hline Weak invariance (Model 2) & 294.24 & 47 & 0.97 & 0.13 & \multicolumn{3}{|c|}{ Model 1 vs. Model 2} & 39.96 & 7 & $<0.001$ \\
\hline Strong invariance (Model 3) & 292.25 & 62 & 0.97 & 0.10 & \multicolumn{3}{|c|}{ Model 2 vs. Model 3} & -3.88 & 15 & 1.00 \\
\hline Partial invariance (Model 4) & 259.96 & 45 & 0.99 & 0.09 & \multicolumn{3}{|c|}{ Model 1 vs. Model 4} & 10.14 & 5 & 0.07 \\
\hline \multicolumn{11}{|l|}{ Externalizing behavioral difficulties } \\
\hline Configural invariance (Model 1) & 191.19 & 70 & 0.79 & 0.06 & & & & & & \\
\hline Weak invariance (Model 2) & 226.78 & 79 & 0.81 & 0.06 & \multicolumn{3}{|c|}{ Model 1 vs. Model 2} & 15.63 & 9 & 0.08 \\
\hline Strong invariance (Model 3) & 293.66 & 88 & 0.74 & 0.07 & \multicolumn{3}{|c|}{ Model 2 vs. Model 3} & 73.45 & 9 & $<0.001$ \\
\hline \multicolumn{11}{|l|}{ Internalizing behavioral difficulties } \\
\hline Configural invariance (Model 1) & 182.58 & 70 & 0.93 & 0.06 & & & & & & \\
\hline Weak invariance (Model 2) & 243.05 & 79 & 0.92 & 0.06 & \multicolumn{3}{|c|}{ Model 1 vs. Model 2} & 33.93 & 9 & $<0.001$ \\
\hline Strong invariance (Model 3) & 303.26 & 88 & 0.89 & 0.07 & \multicolumn{3}{|c|}{ Model 2 vs. Model 3} & 124.06 & 9 & $<0.001$ \\
\hline Partial invariance (Model 4) & 201.28 & 75 & 0.96 & 0.05 & \multicolumn{3}{|c|}{ Model 1 vs. Model 4} & 11 & 5 & 0.05 \\
\hline \multicolumn{11}{|l|}{ Daily material stress } \\
\hline Configural invariance (Model 1) & 52.08 & 18 & 0.99 & 0.09 & & & & & & \\
\hline Weak invariance (Model 2) & 65.98 & 23 & 0.99 & 0.07 & \multicolumn{3}{|c|}{ Model 1 vs. Model 2} & 8.94 & 5 & 0.11 \\
\hline Strong invariance (Model 3) & 99.86 & 34 & 0.98 & 0.09 & \multicolumn{3}{|c|}{ Model 2 vs. Model 3} & 94.36 & 11 & $<0.001$ \\
\hline \multicolumn{11}{|l|}{ Perceived discrimination } \\
\hline Configural invariance (Model 1) & 218.25 & 54 & 0.93 & 0.09 & & & & & & \\
\hline Weak invariance (Model 2) & 228.08 & 62 & 0.94 & 0.08 & \multicolumn{3}{|c|}{ Model 1 vs. Model 2} & 5.89 & 8 & 0.66 \\
\hline Strong invariance (Model 3) & 247.12 & 79 & 0.93 & 0.08 & \multicolumn{3}{|c|}{ Model 2 vs. Model 3} & 25.81 & 17 & 0.08 \\
\hline \multirow[t]{7}{*}{$\begin{array}{l}\text { Table } 4 \text { Fit indices of } \\
\text { final models }\end{array}$} & & & & $\chi^{2}$ & $\mathrm{df}$ & $p$ & TLI & CFI & RMSEA & SRMR \\
\hline & \multicolumn{3}{|l|}{ CRIES-8 } & 259.96 & 45 & $<0.001$ & 0.99 & 0.99 & 0.08 & 0.05 \\
\hline & \multicolumn{3}{|c|}{ Externalizing behavioral difficulties } & 107.58 & 64 & $<0.001$ & 0.97 & 0.98 & 0.03 & 0.06 \\
\hline & \multicolumn{3}{|c|}{ Internalizing behavioral difficulties } & 201.28 & 75 & $<0.001$ & 0.94 & 0.95 & 0.06 & 0.07 \\
\hline & Daily mate & stres & & 520.79 & 18 & $<0.001$ & 0.99 & 0.99 & 0.06 & 0.05 \\
\hline & Perceived & crimir & & 120.88 & 50 & $<0.001$ & 0.98 & 0.99 & 0.05 & 0.07 \\
\hline & Full SEM & & & 5416.70 & 2511 & $<0.001$ & 0.97 & 0.96 & 0.04 & 0.08 \\
\hline
\end{tabular}

Looking at self-reported PTSS on the CRIES-8, 44.7\% of refugee participants who completed all of the items scored within the clinical range, compared to $32.4 \%$ of the non-refugee migrant participants. A chi-square test of independence showed that refugees were more likely than their non-refugee migrant peers to score within the clinical range for PTSS, $X^{2}(1, N=1226)=18.032, p=<0.001$, with refugee participants having 1.69 (95\% CI 1.32-2.15) times the odds of experiencing such symptoms than nonrefugee migrants.

For total behavioral difficulties, $7.6 \%$ of refugee participants and $10.3 \%$ of non-refugee migrant participants for whom a cut-off could be computed, scored high. A chisquare test of independence was again performed to examine the relation between refugee or non-refugee migrant status and total self-reported emotional and
Table 5 Mental health in refugee and non-refugee migrant participants

\begin{tabular}{llll}
\hline & Total group & Refugees & $\begin{array}{l}\text { Non-refugee } \\
\text { migrants }\end{array}$ \\
\hline PTSS & $N=1226$ & $N=772$ & $N=454$ \\
& $13.32(10.79)$ & $14.59(10.65)$ & $11.17(10.70)$ \\
Total behavioral & $N=1202$ & $N=766$ & $N=436$ \\
difficulties & $11.00(5.68)$ & $10.78(5.65)$ & $11.39(5.72)$ \\
Internalizing & $N=1254$ & $N=797$ & $N=457$ \\
behavioral & $6.10(3.48)$ & $6.13(3.42)$ & $6.06(3.57)$ \\
difficulties & $N=1243$ & $N=799$ & $N=444$ \\
$\begin{array}{l}\text { Externalizing } \\
\text { behavioral }\end{array}$ & $4.87(3.24)$ & $4.64(3.19)$ & $5.28(3.30)$ \\
difficulties & $N=1313$ & $N=843$ & $N=470$ \\
Overall well-being & $N=3.97(0.95)$ \\
\hline
\end{tabular}

Mean $(S D)$ 
Table 6 Clinical Categorization (\%) of PTSS, Total, Internalizing and Externalizing Behavioral Difficulties

\begin{tabular}{lllll}
\hline & Total group $(\%)$ & Refugees $(\%)$ & Non-refugee migrants $(\%)$ & $X^{2}(p)$ \\
\hline PTSS & $N=1226$ & $N=772$ & $N=454$ & $18.03(<0.001)$ \\
Below cut-off & 59.9 & 55.3 & 67.6 & \\
Above cut-off & 40.1 & 44.7 & 32.4 & $2.68(0.102)$ \\
Total behavioral difficulties & $N=1202$ & $N=766$ & $N=436$ & \\
Below cut-off & 91.4 & 92.4 & 89.7 & $0.83(0.363)$ \\
Above cut-off & 8.6 & 7.6 & 10.3 & \\
Emotional problems & $N=1294$ & $N=827$ & $N=467$ & $1.91(0.168)$ \\
Below cut-off & 90.5 & 91.1 & 89.5 & \\
Above cut-off & 9.5 & 8.9 & 10.5 & $5.02(0.025)$ \\
Behavioral problems & $N=1286$ & $N=824$ & $N=462$ & \\
Below cut-off & 93.1 & 93.8 & 91.8 & \\
Above cut-off & 6.9 & 6.2 & 8.2 & \\
Hyperactivity & $N=1268$ & $N=814$ & $N=454$ & $0.28(0.595)$ \\
Below cut-off & 93.3 & 94.5 & 91.2 & \\
Above cut-off & 6.7 & 5.5 & 8.8 & \\
Peer problems & $N=1268$ & $N=806$ & $N=462$ & \\
Below cut-off & 89.4 & 89.7 & 88.7 & \\
Above cut-off & 10.6 & 10.3 & 11.3 & \\
Prosocial behavior & $N=1295$ & $N=827$ & $N=468$ & \\
Below cut-off & 96.1 & 96.7 & 94.9 & \\
Above cut-off & 3.9 & 3.3 & 5.1 & \\
\hline
\end{tabular}

behavioral difficulties. The relation between these variables was insignificant, $X^{2}(1, N=1202)=2.68, p=$ 0.102 . Looking at the five SDQ subscales, between $3.3 \%$ and $11.3 \%$ of refugees and non-refugee migrants who received a cut-off score, scored high on emotional problems (refugees: 8.9\%; non-refugee migrants: $10.5 \%$ ), conduct problems (refugees: 6.2\%; non-refugee migrants: $8.2 \%$ ), peer problems (refugees: 10.3\%; non-refugee migrants: $11.3 \%$ ) and low on prosocial behavior (refugees: $3.3 \%$; non-refugee migrants: $5.1 \%$ ). No significant differences between the two participant groups emerged on these scales. With regard to hyperactivity, non-refugee migrants $(8.8 \%)$ were more likely than their refugee peers $(5.5 \%)$ to score within the high range, $X^{2}(1, N=1268)=$ $5.02, p=0.025$.

Further SEM-analyses showed older age to be related to more PTSS in refugees $(t(3395.06)=3.456, S E=$ $0.02, \beta=0.09, p=0.001)$, and more PTSS $(t(27.84)=$ 3.895, $S E=0.039, \quad \beta=0.171, p=0.001)$, internalizing behavioral difficulties $(t \quad(46.6)=2.354, \quad S E=0.027$, $\beta=0.097, \quad p=0.023)$ and lower overall well-being $(t(161.66)=-3.41, S E=0.052, \beta=-0.173, p=0.001)$ for non-refugee migrant participants. For the latter, gender was shown to interact with age and overall well-being, with a significantly sharper decrease in overall well-being with age for female compared to male participants.
SEM-analyses showed no significant association between time in resettlement and any of the outcome measures of mental health.

In sum, these results on participants' mental health only partly confirm the study's first hypothesis, namely that all participants would experience considerable mental health difficulties. Looking at the clinical categorizations presented in Tables $6,40.1 \%$ of the total participant sample reported high levels of PTSS, while only $1.7-8.8 \%$ of the general population has been found to develop full or partial PTSD in the wake of traumatic life events (Lukaschek et al., 2013). Looking at behavioral difficulties on the other hand, the $8.6 \%$ of participants reporting high total levels of behavioral difficulties, corresponds to prevalence rates described in population-based surveys (e.g., Wright et al., 2020). The second study hypothesis, stating that refugees would experience more mental health difficulties than non-refugee migrants in our sample, was also partly confirmed. Refugees in our sample were more likely than non-refugee migrant participants to experience high levels of PTSS. In contrast, non-refugee migrant participants in our sample were more likely than their refugee peers to score high on hyperactivity, measured by the SDQ. The other outcome measures of mental health did not show any significant differences between the two participant groups. 


\section{The Role of Family Separation, Daily Material Stress and Perceived Discrimination in Refugee and Non- refugee Migrant Young People's Mental Health (Hypothesis 3)}

The means and standard deviations of variables measuring daily material stress and perceived discrimination are presented in Table 7.

\section{Family separation}

In the group of refugee participants, $36.35 \%$ indicated to have been separated from family members during migration, compared to $24.85 \%$ of non-refugee migrant participants. Analyses yielded that refugees had 1.73 times the odds (95\% CI 1.35 2.21) than non-refugee migrants to report separation from family members during migration, $X^{2}(1, N=1366)=18.92$, $p=<0.001$. For refugee participants, SEM analyses further showed that the occurrence of family separation was related to worse mental health outcomes in terms of PTSS measured by the CRIES-8 $(t(2513.51)=3.232, S E=0.059, \beta=0.253$, $p=0.001$ ), and internalizing behavioral difficulties measured by the SDQ $(t(158.56)=2.239, S E=0.054, \beta=0.189, p=$ 0.027). For non-refugee migrant participants, no significant relationship existed between separation from family members and any of the mental health outcomes.

\section{Daily material stress}

Refugee young people experienced more daily material stress in resettlement than their non-refugee migrant peers $(t(1332.192)=-5.085, S E=0.067, p=<0.001)$. In both refugee participants $(t$ (inf.) $=6.678, S E=0.049, \quad \beta=$ $0.292, p=0.00)$ and non-refugee migrant participants $(t \quad 674.099)=2.096, \quad S E=0.06, \quad \beta=0.119, \quad p=0.036)$ higher levels of daily material stress related to decreased levels of overall well-being. For refugees, but not for nonrefugee migrants, higher daily material stress further related

Table 7 Daily material stress and perceived discrimination in refugee and non-refugee migrant participants

\begin{tabular}{llll}
\hline & Total group & Refugees & $\begin{array}{l}\text { Non-refugee } \\
\text { migrants }\end{array}$ \\
\hline Daily material stress & $N=1338$ & $N=864$ & $N=474$ \\
& $3.46(0.70)$ & $3.39(0.72)$ & $3.59(0.63)$ \\
Perceived & $N=1285$ & $N=821$ & $N=464$ \\
discrimination & $1.41(0.45)$ & $1.38(0.42)$ & $1.46(0.49)$ \\
\hline
\end{tabular}

Mean $(S D)$

Minimum and maximum item scores: 1-4. Hereby, higher scores on Daily material stress mean a lesser level of daily stress, while higher scores on Perceived discrimination reflect a higher level of perceived discrimination to higher levels of mental health symptomatology, in terms of both internalizing $(t(37,09)=-4.1, S E=0.031, \beta=-$ $0.189, p=0.00)$ and externalizing $(t(48.613)=-2.856$, $S E=0.034, \beta=-0.139, p=0.006$ ) behavioral difficulties.

\section{Perceived discrimination}

Non-refugee migrants reported higher levels of perceived discrimination than refugees $(t(1020.586)=-2.887, S E=$ $0.043, p=0.004)$. The model showed that for all participants perceived discrimination in resettlement was associated with lower overall well-being and higher levels of mental health symptomatology across all measures. In refugee participants, this was thus the case for PTSS $(t(594.713)=5.176, S E=$ $0.069, \beta=0.256, p=<0.001)$, internalizing behavioral difficulties $(t \quad(293.17)=8.415, \quad S E=0.063, \quad \beta=0.471, \quad p=$ $<0.001)$, externalizing behavioral difficulties $(t(88.454)=$ 9.472, $S E=0.075, \beta=0.587, p=<0.001)$, and overall wellbeing $(t(33.118)=-3.419, S E=0.086, \beta=-0.158, p=$ 0.002 ), as well as in non-refugee migrants for PTSS $(t \quad(221.683)=6.282, \quad S E=0.085, \quad \beta=0.354, \quad p=<0.001)$, internalizing behavioral difficulties $(t(217.351)=8.26, S E=$ $0.077, \beta=0.552, p=<0.001$ ), externalizing behavioral difficulties $(t \quad(367.621)=9.718, \quad S E=0.087, \quad \beta=0.735, \quad p=$ $<0.001)$, and overall well-being $(t(91.262)=-6.477, S E=$ $0.099, \beta=-0.355, p=<0.001$ ).

In sum, these results partly confirm the study's third hypothesis, namely that the negative impact of family separation, daily material stress and perceived discrimination on mental health would be greater in refugees than nonrefugee migrants. Analysis showed that refugees' mental health was impacted more by experiences of family separation and daily material stress than that of non-refugee migrant participants. However, perceived discrimination posed equal risks to the mental health of both groups.

\section{Complementary and Alternative Analyses}

Because of the broad range of the numbers of years participants spent in resettlement, an additional and separate sensitivity analysis was performed including only the young people that had resided in the host country for five years or less (Shakya et al., 2010). It had to be concluded that the model did no longer converge. Hereby, this manuscript has now reported on all design and procedural details, all data, all the analyses and results of this study.

\section{Discussion}

Recent systematic reviews suggest that being a migrant to Europe forms a risk for adjustment and mental health (e.g., Kouider et al., 2014). While the existing evidence shows 
that both refugee and non-refugee migrant young people display increased levels of psychosocial vulnerability, scholarly work comparing the mental health of both groups is scarce. This study therefore sought to document and compare refugee and non-refugee migrants' mental health in a large-scale sample of young people within European secondary education. It assessed post-traumatic stress symptoms, externalizing and internalizing behavioral difficulties and overall well-being, and examined the role of family separation, daily material stress and perceived discrimination in young people's mental health.

\section{Refugee and Non-refugee Migrant Young People's Mental Health}

The $8.6 \%$ of participants who scored high on total behavioral difficulties measured by the SDQ, corresponds to prevalence rates described in population-based surveys (e.g., Wright et al., 2020). However, in terms of PTSS, study participants scored noticeably higher than expected based on population-based research (e.g., Lukaschek et al., 2013 ), with $40.1 \%$ of the total sample, $44.7 \%$ of refugees and $32.4 \%$ of non-refugee migrants scoring within the clinical range for PTSS.

For refugees, the high levels of PTSS corroborate previous research that unequivocally documents elevated levels of PTSD in refugee children and young people, with recent estimates of PTSD prevalence rates between 19 and 52.7\% (Kien et al., 2018). Within the range of prevalence rates reported in previous studies, the proportion of refugees in this study scoring within the clinical range for PTSS is situated rather on the high end of this prevalence interval. For non-refugee migrants, a paucity of studies have documented the prevalence of PTSD. Here, albeit displaying a smaller proportion of young people scoring above the clinical cut-off for PTSS as compared to refugee participants, these study findings indicate how non-refugee migrant young people may equally form a highly vulnerable population to the development of post-traumatic stress. Furthering the scarce existing evidence on post-traumatic stress in non-refugee migrant children and adolescents (Derluyn et al., 2008; Jaycox et al., 2002; Kevers et al., under review), this study provides novel evidence on PTSS in non-refugee migrant young people in Europe, raising important questions on those traumatic stressors that characterize their life trajectories. The study's findings on increased levels of PTSS in both refugee and non-refugee migrant young people may suggest that the latter, albeit not fleeing their home countries pursuing safety from war and prosecution, may experience other traumatic stressors, preceding, during or following their migration, and further research is needed to develop a more in-depth understanding of those traumatic stressors that characterize migration trajectories and resettlement conditions in these young people. First, an important source of hypotheses on trauma exposure is the concern amongst scholars and policy-makers in Europe on the atrocities and hardships faced by both refugee and non-refugee migrant young people along their migration routes (Derluyn et al., 2009). Indeed, while for some non-refugee migrants (e.g., from Eastern-European countries) migration into Europe may occur through legal travel across European member states, other non-refugee migrants may experience severe forms of hardship, exposed to violence underway, in the hands of smugglers or residing in transit or border camps. Second, traumatic stressors occurring in resettlement might include experiences of community or domestic violence in these young people's families (e.g., Gray et al., 2014; Jaycox et al., 2002), with existing studies indicating the role of low socio-economic status, material stress, and cultural loss imbuing family relationships in the development of intrafamily conflict (e.g., Kiamanesh \& Hauge, 2019; Leyendecker et al., 2018).

In further understanding these findings on high levels of PTSS in refugee and non-refugee migrant young people, it is important to address the extent to which high levels of PTSS correspond to experiences of impairment and dysfunctioning in young people's development. In this study, the discrepancy between the high levels of PTSS and lower levels of internalizing and externalizing behavioral difficulties as well as rather positive levels of overall well-being, generates an interest into understanding how elevated PTSS may coexist with relatively adequate functioning and adaptation, a finding that several previous studies have indicated (Rousseau et al., 2007). This potential concurrence of PTSS and adaptive functioning resonates the critical scrutiny of PTSD as a diagnostic construct in accounting for refugees' suffering. Indeed, studies address the psychometric complexities of a valid transcultural trauma assessment (e.g., Gadeberg et al., 2017), and scholars emphasized how, although many refugees do report post-traumatic stress symptoms, this vocabulary of post-traumatic stress may not fully capture their multilayered responses invoked by traumatization, including loss and cultural bereavement, guilt, shame, or specific cultural idioms of distress (e.g., Kevers et al., 2016; Kirmayer, 2007). Further, given the central role of young people's school trajectories in social integration and identity formation as a central developmental task during adolescence, the study's findings on elevated levels of PTSS in refugee and non-refugee migrant young people raise important questions on the level of impairment in young people's individual and relational functioning, including the impact of PTSS on their school development. In school settings in particular, it seems paramount to understand the impact of PTSS on young 
people's school functioning, their abilities in acquiring the host country language and academic proficiency. Previous research documented the potentially negative sequelae of traumatic distress in refugee children and adolescents, including disrupted concentration, agitation and arousal, sleep deprivation, and impaired language development (e.g., Fazel \& O'Higgins, 2020; Kaplan et al., 2016). Further research is needed to broaden the understanding of how post-traumatic functioning in both refugee and non-refugee migrant young people affect school trajectories, especially given the ample evidence of complicated and often disrupted academic trajectories of migrant children and adolescents, as consistently reported across Europe (UNHCR et al., 2019).

\section{The Role of Family Separation, Daily Material Stress and Perceived Discrimination in Refugee and Non- refugee Migrant Young People's Mental Health}

\section{Family separation}

Migration-related family separation was more prevalent in refugee than in non-refugee migrant participants, associated with higher levels of both PTSS and internalizing behavioral difficulties in the former. These findings resonate with studies on the pervasive impact of family separation on refugee children and adolescents' mental health (e.g., Miller et al., 2018). In non-refugee migrant participants, no relationship was found between separation and mental health problems. Several factors might explain this difference. First, the literature suggest that separation begets a more traumatic nature when resulting from armed conflict, political, ethnic or religious persecution (Suarez-Orozco et al., 2002). Fear for the safety of family members remaining in a country of origin afflicted by organized violence has previously been described to act as a severe source of distress and (indirect) traumatization in refugees (e.g., Miller et al., 2018). Therefore, separation perhaps more often was of a traumatic nature in refugee than in non-refugee migrant families. Second, parental availability in the aftermath of separation may operate as a buffer against its negative mental health sequelae in children. Studies on refugee family functioning indeed describe how, as a result of cumulative distress, diminished parental availability may complicate the impact of forced migration stressors on child development and mental health (De Haene et al., 2010; De Haene \& Rousseau, 2020a).

\section{Daily material stress}

A higher level of daily material stress was associated with decreased levels of overall well-being in all participants.
For refugee young people as opposed to their non-refugee migrant peers, daily material stress furthermore corresponded to higher levels of internalizing and externalizing behavioral difficulties. The fact that in refugees but not in non-refugee migrants, daily material stress was found to be associated with higher mental health vulnerability in addition to a lower well-being, could perhaps be understood in light of the numerous, complex losses that characterize the refugee experience (McLellan, 2015). Stressful post-flight living conditions, including the experience of material strain, may echo broader personal, familial, social and cultural bereavement following collective violence and forced displacement and compound their impact (e.g., Cissé et al., 2020).

\section{Perceived discrimination}

Higher levels of perceived discrimination related to lower overall well-being and worse mental health outcomes on all measures for both refugee and non-refugee migrant participants. An ample body of research describes the impact of discrimination on migrants' mental health, with an emphasis on adaptation difficulties (Buchanan et al., 2018), psychological distress and symptoms of internalizing disorders (e.g., Beiser \& Hou, 2016). For refugees specifically, previous findings provide additional evidence for the relationship between experiences of discrimination and PTSDsymptomatology (e.g., Ellis et al., 2010). In psychosocial refugee literature, experiences of discrimination in resettlement are understood to reiterate, aggravate or reactivate past traumatic suffering rooted in experiences of human rights violations in refugees' home societies or during flight (Alemi \& Stempel, 2018; De Haene \& Rousseau, 2020b).

Noteworthy in this study, however, is the association between perceived discrimination and PTSS for nonrefugee migrants. To previous knowledge, this study is the first to document this association for the particular group of non-refugee migrant young people. In light of the remarkably high levels of PTSS in the subsample of nonrefugee migrant participants and the question raised by this finding on the particular forms of trauma exposure in nonrefugee migrant young people, it seems important to question how experiences of discrimination in resettlement may interact with other traumatic stressors in predicting PTSS. For example, authors referring to migrant young people's migration trajectories to the U.S. as "painful passages" (Perreira and Ornelas, 2013), provide evidence for the way post-settlement experiences of discrimination may exacerbate the traumatic impact of stressors during the migration trajectory. In particular, one of these stressors might in fact concern discrimination, at the time potentially interwoven with other traumatic experiences, such as detention, severe deprivation and (sexual) violence and exploitation. Future 
research is needed to further explore young people's lived experiences of discrimination in relation to their migration trajectories, their meaning-making of perceived discrimination and the role of school in aggravating or coping with these experiences.

Overall, these findings support the need for the development of accessible mental healthcare services for refugee and non-refugee young people in Europe. In developing mental health care provisions, the social nature of stressors of discrimination call for an approach that combines specialized support for young people with mental health problems with accessible care within community settings. Increasingly, scholars call for the implementation of preventive mental health programs within school settings (e.g., Franco, 2018; Papazian-Gohrabian et al., 2020). Schools, as community spaces, are increasingly underscored as important spaces in which refugee and non-refugee migrant young people navigate their socio-emotional development, shaping life and adaptation in resettlement (Schachner et al., 2018). Furthermore, school-based everyday interactions with peers and school actors may become easily imbued with broader macrosocietal dynamics, leading to a reiteration or buffering of broader social dynamics of discrimination or exclusion. Therefore, engaging with school-based forms of mental health intervention for refugees and non-refugee migrants may allow supporting young people in coping with distress while equally addressing those social predicaments that so strongly provoke it.

\section{Study Strengths and Limitations}

The presented study has several important strengths. A first strength concerns its comparison between refugee and nonrefugee migrant young people's mental health, an issue only a limited number of previous studies have addressed. A second strength of the study lies in its relatively large sample size obtained in an otherwise difficult to reach study population (Enticott et al., 2017; Fête et al., 2019). In line with scholars emphasizing the importance of autonomy and agency of refugee and migrant participants in research practices (e.g., de Smet et al., 2020), a third strength of the study lies in the way it engaged in an active, tailored and iterative process of obtaining and negotiating informed consent with participants, as well as with their parents. In addition, the translation of study materials (informed consent forms, questionnaires) and the collaboration with qualified interpreters in several countries and in different stages of the study, aimed to foster this process of a shared understanding and negotiation of research participation. In sum, this study forms an important addition to the existing body of scholarly work on the mental health of refugee and non-refugee migrant young people in Europe.
Nevertheless, the study also has several limitations that should be noted. A first shortcoming of this study lies in its one-sided emphasis on its participants' mental health difficulties. Besides reading vulnerability in the study sample, it is of equal importance to consider the number of participants not reporting increased levels of mental health difficulties, and therewith to acknowledge young people's resilience. Previous scholarly work indeed highlights refugee and non-refugee migrant young people's capacity for growth, adaptive development and relational connectedness even in the aftermath of traumatizing life experiences (e.g., Pieloch et al., 2016). Second, although discussing the possibility of repeated traumatization and complex processes of interwoven traumatic suffering in both subgroups within the sample, the study's methodology in itself did not allow for any definitive conclusions supporting these assumptions. The item on family separation was incapable of precisely capturing the nature or family separation, more specifically whether it occurred prior to, during or after migration, as well as whether or not it continued to last in resettlement. It also did not inquire which family members young people were separated from, and if separation concerned their nuclear family unit or rather extended family members. Further, little was known about the heterogeneousness of migration trajectories, especially in the non-refugee migrant subsample. The study contained no measures on the prevalence or nature of stressors occurring prior to or during migration, other than family separation. It was therefore impossible to explore chronological patterns of trauma exposure, and their role in the development of PTSS. Future research could examine this further, and would perhaps also benefit from a more scrupulous categorization of refugees and non-refugee migrants into different subgroups. Third, on the level of the statistical analyses it is important to note that some of the latent constructs in the study only showed partial measurement invariance, suggesting they might refer to slightly different characteristics within the two categorized subgroups. Also, as shown in Table 2, the omega statistics of the SDQ externalizing subscale in both the refugee and non-refugee migrant subgroup, as well as the SDQ internalizing subscale in the refugee subgroup were below 0.70 , and should as such be interpreted with a certain level of caution (Nunnally \& Bernstein, 1994). Fourth, due to its cross-sectional design, the study does not allow to draw conclusions about causality or directions of effects. For instance, it is possible that experiences of discrimination contribute to internalizing and externalizing behavioral difficulties, but based on the presented findings, the reverse could also be true, i.e., that internalizing and externalizing behavioral difficulties make young people easier targets for discrimination. Fifth, a larger sample size would have increased analytical power. Albeit, as indicated above, in the studied population, the current sample size is certainly 
deemed acceptable (Enticott et al., 2017; Fête et al., 2019). Sixth, the data were not modeled in a way that made it possible to account for potential contextual level differences, for example, on the level of the host country, school or class, in the mental health and experiences of refugees and non-refugee migrants in our study. Seventh, testing for measurement invariance between groups, we consistently used the first item of the measure as the reference indicator for the latent variable. Future work, however, could engage in a more nuanced consideration of the reference indicator selection when testing for measurement invariance (e.g., Thompson et al., 2021). Lastly, the outcomes and conclusions presented apply only to the countries in which the data for this study were collected. As such, findings cannot be reliably generalized to refugee and non-refugee migrant young people resettling elsewhere in the world.

\section{Conclusion}

Albeit an important and timely public health concern across European host societies, sufficiently powered studies on refugee and non-refugee migrant young people's mental health are lacking. Studies comparing the mental health of the two groups remain particularly scarce. This study sought to document and compare refugee and nonrefugee migrant young people's mental health in a largescale sample of participants within European secondary education $(N=1366)$, and in relation to their migration history and resettlement conditions. The results of this study confirm refugee and non-refugee migrant young people in European secondary education to be at significant risk for the development of mental health problems, with refugees showing slightly higher levels of post-traumatic stress symptomatology and decreased mental health related to family separation and daily material stress than non-refugee migrants. Perceived discrimination was linked with all measures of mental health and well-being in both refugee and non-refugee migrant participants. The relationship between perceived discrimination and post-traumatic stress symptoms in nonrefugee migrants, together with the high levels of posttraumatic stress symptoms in this subsample, raises important questions on the nature of trauma exposure in non-refugee migrants, as well as the ways in which experiences of discrimination may interact with other traumatic stressors in predicting mental health. These findings highlight the need for the development of adequate mental healthcare services for refugee and nonrefugee young people in Europe, preferably broadening a focus on individual well-being by engaging with social and societal dynamics that shape the mental health of these young people.
Acknowledgements First and foremost, we owe thanks to the young people, their teachers and school staff who committed to this research project with great care and sincerity. We are furthermore grateful to all of our RefugeesWellSchool consortium partners, for the durable and thought-provoking collaboration of which this article is an outcome. In name of the first author: Dank je, Lucia, voor alles waar dit artikel voor staat.

Authors' Contributions CS was responsible for study supervision, school and participant recruitment and data collection in the Belgium research context, participated in the performance and interpretation of and drafted this manuscript; AV coordinated the overall RefugeesWellSchool study, co-supervised this study, participated in the design of the data and analyses, and reviewed different drafts of the manuscript; ID (Ines Devlieger) designed and performed the statistical analyses, advised and assisted in their interpretation, and wrote the paragraphs on "Analysis" and "Measurement Invariance and Fit"; SA was responsible for study supervision, school and participant recruitment and data collection in the Finnish research context, and reviewed different drafts of the manuscript; AA was responsible for study supervision, school and participant recruitment and data collection in the Norwegian research context; ND was responsible for study supervision, school and participant recruitment and data collection in the Swedish research context, participated in the design of the data for this study and reviewed different drafts of the manuscript; PKH was responsible for study supervision, school and participant recruitment and data collection in the Norwegian research context, and reviewed different drafts of the manuscript; RK was responsible for study supervision, school and participant recruitment and data collection in the Finnish research context, participated in the design of the data for this study and reviewed different drafts of the manuscript; NLP was responsible for study supervision, school and participant recruitment and data collection in the Danish research context, participated in the design of the data for this study and reviewed different drafts of the manuscript; MO supervised the study and data collection in the Norwegian research context, participated in the design of the data for this study, and reviewed different drafts of the manuscript; $\mathrm{FO}$ was responsible for study supervision, school and participant recruitment and data collection in the Swedish research context, and reviewed different drafts of the manuscript; KP was responsible for study supervision, school and participant recruitment and data collection in the Finnish research context, and reviewed different drafts of the manuscript; AS was responsible for study supervision in the Swedish research context; MS was responsible for study supervision in the Danish research context and reviewed different drafts of the manuscript; SSJ was responsible for study supervision in the Danish research context and reviewed different drafts of the manuscript; ES reviewed different drafts of the manuscript; CW participated in the design and supervision of the overall RefugeesWellSchool study of which this study forms part; ID (Ilse Derluyn) supervised the RefugeesWellSchool study and reviewed different drafts of the manuscript; HC co-supervised the implementation of the RWS study in the Belgium research context and participated in editing of all drafts of the manuscript; LDH was responsible for study supervision in the Belgian research context, participated in design of this study, the analysis, in the interpretation of research results, the writing and substantial editing of all drafts of the manuscript. All authors read and approved the final manuscript.

Funding This project has received funding from the European Union's Horizon 2020 research and innovation program under grant agreement No. 754849.

Data Sharing Declaration The manuscript's data will not be deposited. 


\section{Compliance with Ethical Standards}

Conflict of Interest The authors declare no competing interests.

Ethical Approval Ethics approval for the overall RefugeesWellSchool project was granted by the University of Ghent's Ethics Commission. Additionally, each country involved in the research obtained ethical approval from their respective national Ethics Commission.

Informed Consent Informed consent was obtained for young people and their parents, in accordance with national ethical guidelines on conducting research with minors.

Publisher's note Springer Nature remains neutral with regard to jurisdictional claims in published maps and institutional affiliations.

\section{Appendix: A Measures, Items and Corresponding Scoring}

\begin{tabular}{|c|c|c|c|}
\hline Measure & Items & $\begin{array}{l}\text { Response } \\
\text { options }\end{array}$ & Scoring \\
\hline \multirow[t]{2}{*}{$\begin{array}{l}\text { Family } \\
\text { Separation }\end{array}$} & $\begin{array}{l}\text { Where you ever } \\
\text { separated from } \\
\text { family members } \\
\text { during your } \\
\text { migration to this } \\
\text { country? }\end{array}$ & Yes & 1 \\
\hline & & No & 0 \\
\hline \multirow[t]{5}{*}{$\begin{array}{l}\text { Overall Well- } \\
\text { being }\end{array}$} & $\begin{array}{l}\text { How would you } \\
\text { rate your overall } \\
\text { well-being? }\end{array}$ & Very bad & 1 \\
\hline & & Bad & 2 \\
\hline & & Normal & 3 \\
\hline & & Good & 4 \\
\hline & & Very Good & 5 \\
\hline \multirow[t]{3}{*}{$\begin{array}{l}\text { CRIES-8 (Perrin } \\
\text { et al., 2005) }\end{array}$} & $\begin{array}{l}\text { Do you think } \\
\text { about it [stress- } \\
\text { ful life event] } \\
\text { even when you } \\
\text { don't mean to? }\end{array}$ & Not at all & 0 \\
\hline & $\begin{array}{l}\text { Do you try to } \\
\text { remove it } \\
\text { [stressful life } \\
\text { event] from } \\
\text { your memory? }\end{array}$ & Rarely & 1 \\
\hline & $\begin{array}{l}\text { Do have waves } \\
\text { of strong feel- } \\
\text { ings about it }\end{array}$ & Sometimes & 3 \\
\hline
\end{tabular}

Table (continued)

\begin{tabular}{llll}
\hline Measure & Items & $\begin{array}{l}\text { Response } \\
\text { options }\end{array}$ & Scoring \\
\hline
\end{tabular}

[stressful life

event]?

Do you stay

Often

5

away from

reminders of it

[stressful life

event]? (e.g.,

places,

situations)

Do you try not to talk about it [stressful life event]?

Do you pictures about it [stressful life event]

pop into

your mind?

Do other things

keep making you think about it [stressful life event]?

Do you try not to think about it [stressful life event]?

SDQ (Good- I try to be nice Not true 0 man, 1997; to other people.

2001; Goodman I care about

et al., 2000)

their feelings

I am restless, I Somewhat true 1 cannot stay still for long

I get a lot of Certainly true 2 headaches, stomach-aches or sickness I usually share with others (e.g., food, games, pens)

I get very angry and often lose my temper 
Table (continued)

\begin{tabular}{llll}
\hline Measure & Items & $\begin{array}{l}\text { Response } \\
\text { options }\end{array}$ & Scoring \\
\hline
\end{tabular}

I am usually on my own. I generally do things alone or keep to myself

I usually do as I am told

I worry a lot

I am helpful if someone is hurt, upset or feeling ill

I am constantly fidgeting or squirming

I have one good friend or more

I fight a lot, I can make other people do what I want

I am often unhappy, sad or tearful

Other people my age generally like me I am easily distracted, I find it difficult to concentrate

I am nervous in new situations, I easily lose confidence

I am kind to younger children

I am often accused of lying or cheating

Other children or young people
Table (continued)

\begin{tabular}{llll}
\hline Measure & Items & $\begin{array}{l}\text { Response } \\
\text { options }\end{array}$ & Scoring \\
\hline
\end{tabular}

pick on me or

bully me

I often volunteer

to help others

(parents,

teachers, peers)

I think before I

do things

I take things that are not mine

from home,

school or

elsewhere

I get on better

with adults than

with people my

own age

I have many

fears, I am

easily scared

I finish the work

I'm doing, my

attention is good

Daily material

I have enough Never

1

stress (Vervliet food to eat

et al.,

unpublished)

I have enough Sometimes 2

clothing

I have Often

3

enough money

I have an ok

Always

4

place to live

I have enough

medical care

I feel safe

PEDQ - exclu- [Because of

sion and discri- your

mination sub- background...]

scales (Bron-

dolo et al.,

2005)

Have you been

Sometimes

2 
Table (continued)

\begin{tabular}{llll} 
Measure & Items & $\begin{array}{l}\text { Response } \\
\text { options }\end{array}$ & Scoring \\
\hline
\end{tabular}

by principals or

other staff at

school?

Have others Often
thought you
couldn't do
things or handle
a task?

Have policeman Always

4

or security offi-

cers been unfair

to you?

Have you been

treated unfairly

by classmates?

Have others

hinted that you

are dishonest or

can't be trusted?

Has your tea-

cher been unfair

to you?

Have others

suggested you

are dirty?

Have people not

trusted you?

Has it been

hinted that you

must be lazy?

\section{References}

Alemi, Q., \& Stempel, C. (2018). Discrimination and distress among Afghan refugees in northern California: The moderating role of pre- and post-migration factors. PLOS ONE, 13(5), e0196822.

American Psychiatric Association. (2013). Diagnostic and statistical manual of mental disorders (5th ed.). Washington DC: Author.

Bayram Özdemir, S., \& Stattin, H. (2014). Why and when is ethnic harassment a risk for immigrant adolescents' school adjustment? Understanding the processes and conditions. Journal of Youth and Adolescence, 43, 1252-1265.

Beiser, M., \& Hou, F. (2016). Mental health effects of premigration trauma and postmigration discrimination on refugee youth in Canada. The Journal of Nervous and Mental Disease, 204(6), 464-470.

Beiser, M., Goodwill, A. M., Albanese, P., Mcshane, K., \& Kanthasamy, P. (2015). Predictors of the integration of Sri Lankan

Tamil refugees in Canada: pre-migration adversity, mental health, personal attributes, and post-migration experience. International Journal of Migration, Health and Social Care, 11(1), 29-44.

Betancourt, T. S., \& Khan, K. T. (2008). The mental health of children affected by armed conflict: Protective processes and pathways to resilience. International Review of Psychiatry, 20 (3), 317-328.

Betancourt, T. S., Newnham, E. A., Layne, C. M., Soeun, K., Steinberg, A. M., Ellis, H., \& Birman, D. (2012). Trauma history and psychopathology in war-affected refugee children referred for trauma-related mental health services in the United States. Journal of Traumatic Stress, 25, 682-690.

Betancourt, T. S., Newnham, E. A., Birman, D., Lee, R., Ellis, B. H., Layne, C. M., \& Purbeck, C. (2017). Comparing trauma exposure, mental health needs, and service utilization across clinical samples of refugee, immigrant, and U.S.-origin children. Journal of Traumatic Stress, 30, 209-218.

Bird, H. R., Shaffer, D., \& Fisher, P. (1993). The Columbia Impairment Scale (CIS): Pilot findings on a measure of global impairment for children and adolescents. International Journal of Methods in Psychiatric Research, 3, 167-176.

Bourdon, K., Goodman, R., Rae, D., Simpson, G., \& Koretz, D. (2005). The Strengths and Difficulties Questionnaire: US normative data and psychometric properties. Journal of the American Academy of Child and Adolescent Psychiatry, 44(6), 557-564.

Brondolo, E., Kelly, K. P., Coakley, V., Gordon, T., Thompson, S., Levy, E., \& Contrada, R. J. (2005). The Perceived Ethnic Discrimination Questionnaire: Development and preliminary validation of a community version. Journal of Applied Social Psychology, 35(2), 335-365.

Brown, T. A. (2015). Confirmatory factor analysis for applied research. New York: Guilford Press

Browne, M. W., \& Cudeck, R. (1993). Alternative ways of assessing model fit. In K. A. Bollen \& J. S. Long (Eds.), Testing structural equation models (pp. 136-162). Newbury Park, CA: Sage.

Buchanan, Z. E., Abu-Rayya, H. M., Kashima, E., Paxton, S. J., \& Sam, D. L. (2018). Perceived discrimination, language proficiencies, and adaptation: Comparisons between refugee and nonrefugee immigrant youth in Australia. International Journal of Intercultural Relations, 63, 105-112.

van Buuren, S., \& Groothuis-Oudshoorn, K. (2011). mice: Multivariate Imputation by Chained Equations in R. Journal of Statistical Software, 45(3), 1-67.

Byrne, B. M., Shavelson, R. J., \& Muthén, B. (1989). Testing for the equivalence of factor covariance and mean structures: the issue of partial measurement invariance. Psychological Bulletin, 105, $456-466$.

Cissé, A., De Haene, L., Keatley, E., \& Rasmussen, A. (2020). Preand post-migration trauma and adversity: Sources of resilience and family coping among West African refugee families. In L. De Haene \& C. Rousseau (Eds.), Working with refugee families: Trauma and exile in family relationships. Cambridge: Cambridge University Press.

De Haene, L., \& Rousseau, C. (2020b). Working with refugee families: Inscribing suffering and restoration in personal and communal worlds. In L. De Haene \& C. Rousseau (Eds.), Working with refugee families: Trauma and exile in family relationships. Cambridge: Cambridge University Press.

De Haene, L., \& Rousseau, C. (Eds.) (2020a). Working with refugee families: Trauma and exile in family relationships. Cambridge/ New York: Cambridge University Press.

Derluyn, I., Broekaert, E., \& Schuyten, G. (2008). Emotional and behavioural problems in migrant adolescents in Belgium. European Child \& Adolescent Psychiatry, 17(1), 54-62. 
Derluyn, I., Lippens, V., Verachtert, T., Bruggeman, W., \& Broekaert, E. (2009). Minors travelling alone: A risk group for human trafficking? International Migration, 48(4), 164-185.

Dimitrova, R., Chasiotis, A., \& Van De Vijver, F. (2016). Adjustment outcomes of immigrant children and youth in Europe: A metaanalysis. European Psychologist, 21(2), 150-162.

Ellis, B. H., MacDonald, H. Z., Klunk-Gillis, J., Lincoln, A., Strunin, L., \& Cabral, H. J. (2010). Discrimination and mental health among Somali refugee adolescents: The role of acculturation and gender. American Journal of Orthopsychiatry, $80(4), 564-575$.

Enticott, J. C., Shawyer, F., Vasi, S., Buck, K., Cheng, I.-H., Russell, G., ... Meadows, G. (2017). A systematic review of studies with a representative sample of refugees and asylum seekers living in the community for participation in mental health research. BMC Medical Research Methodology, 17(1), 37.

Eurostat (2019). Young people: Migration and socioeconomic situation. Retrieved on December $30^{\text {th }} 2020$ from https://ec.europa.eu/ eurostat/statistics-explained/index.php?title=Young_people_-_ migration_and_socioeconomic_situation.

Fazel, M., \& O'Higgins, A. (2020). Family-school relationships in supporting refugee children's school trajectories In L. De Haene \& C. Rousseau (Eds.), Working with refugee families: Trauma and exile in family relationships. Cambridge: Cambridge University Press.

Fête, M., Aho, J., Benoit, M. et al. (2019). Barriers and recruitment strategies for precarious status migrants in Montreal, Canada. BMC Medical Research Methodology 19(1), 41.

Franco, D. (2018). Trauma without borders: The necessity for schoolbased interventions in treating unaccompanied refugee minors. Child and Adolescent Social Work Journal, 35(6), 551-565.

Gadeberg, A. K., Montgomery, E., Frederiksen, H. W., \& Norredam, M. (2017). Assessing trauma and mental health in refugee children and youth: A systematic review of validated screening and measurement tools. European Journal of Public Health, 27(3), 439-446.

Gindling, T. H., \& Poggio, S. (2012). Family separation and reunification as a factor in the educational success of immigrant children. Journal of Ethnic and Migration Studies, 38(7), 1155-1173.

Goodman, R. (1997). The Strengths and Difficulties Questionnaire: A research note. Journal of Child Psychology and Psychiatry, 38(5), 581-586.

Goodman, R. (2001). Psychometric properties of the Strengths and Difficulties Questionnaire (SDQ). Journal of the American Academy of Child and Adolescent Psychiatry, 40(11), 1337-1345.

Goodman, R., Ford, T., Simmons, H., Gatward, R., \& Meltzer, H. (2000). Using the Strengths and Difficulties Questionnaire (SDQ) to screen for child psychiatric disorders in a community sample. British Journal of Psychiatry, 177, 534-539.

Goodman, A., Lamping, D. L., \& Ploubidis, G. B. (2010). When to use broader internalising and externalising subscales instead of the hypothesised five subscales on the Strengths and Difficulties Questionnaire (SDQ): data from British parents, teachers and children. Journal of Abnormal Child Psychology, 38(8), 1179-1191.

Gray, L., Easteal, P., \& Bartels, L. (2014). Immigrant women and family violence: Will the new exceptions help or hinder victims? Alternative Law Journal, 39(3), 167-171.

Green, H., McGinnity, A., Meltzer, H., Ford, T., \& Goodman, R. (2005). Mental health of children and young people in Great Britain, 2004. Hampshire, UK: Palgrave Macmillan.

De Haene, L., Grietens, H., \& Verschueren, K. (2010). Adult attachment in the context of refugee traumatisation: The impact of organized violence and forced separation on parental states of mind regarding attachment. Attachment \& Human Development, 12, 249-264.
Hassan, G., Rousseau, C., \& Moreau, N. (2013). Ethnic and religious discrimination: The multifaceted role of religiosity and collective self-esteem. Transcultural Psychiatry, 50(4), 475-492.

Hirschfeld, G., \& von Brachel, R. (2014). Improving Multiple-Group confirmatory factor analysis in R-A tutorial in measurement invariance with continuous and ordinal indicators. Practical Assessment, Research \& Evaluation, 19(7), 1-12.

Hjern, A., \& Jeppsson, O. (2005). Mental health care for refugee children in exile. In D. Ingleby (Ed.), Forced migration and mental health. Rethinking the care of refugees and displaced persons (pp. 115-127). New York: Springer.

Hodes, M., \& Vostanis, P. (2019). Practitioner review: Mental health problems of refugee children and adolescents and their management. The Journal of Child Psychology and Psychiatry, 60(7), 716-731.

Hu, L., \& Bentler, P. M. (1999). Cutoff criteria for fit indexes in covariance structure analysis: Conventional criteria versus new alternatives. Structural Equation Modeling, 6, 1-55.

International Organisation for Migration (2019). World Migration Report 2020. Geneva: International Organisation for Migration.

Jaycox, L. H., Stein, B. D., Kataoka, S. H., Wong, M., Fink, A., Escudero, P., \& Zaragoza, C. (2002). Violence exposure, posttraumatic stress disorder, and depressive symptoms among recent immigrant schoolchildren. Journal of the American Academy of Child \& Adolescent Psychiatry, 41(9), 1104-1110.

Jorgensen, T. D., Pornprasertmanit, S., Schoemann, A. M., \& Rosseel, Y. (2020). SemTools: Useful tools for structural equation modeling. R package version 0.5-3. Retrieved from https://CRAN.Rproject.org $/$ package $=$ semTools.

Kaplan, I., Stolk, Y., Valibhoy, M., Tucker, A., \& Baker, J. (2016). Cognitive assessment of refugee children: Effects of trauma and new language acquisition. Transcultural Psychiatry, 53(1), 81-109.

Keles, S., Friborg, O., Idsøe, T., Sirin, S., \& Oppedal, B. (2016). Depression among unaccompanied minor refugees: The relative contribution of general and acculturation-specific daily hassles. Ethnicity \& Health, 21(3), 300-317.

Kevers, R. \& Rober, P., Derluyn, I. \& De Haene, L. (2016). Remembering collective violence: Broadening the notion of traumatic memory in post-conflict rehabilitation. Culture, Medicine, \& Psychiatry, 40, 620-640.

Kevers, R., Spaas, C., Colpin, H., Van Den Noortgate, W., de Smet, S., Derluyn, I., \& De Haene, L. (2021). Mental health problems in refugee and immigrant primary school children in Flanders, Belgium.

Kiamanesh, P., \& Hauge, M. (2019). "We are not weak, we just experience domestic violence": Immigrant women's experiences of encounters with service providers as a result of domestic violence. Child \& Family Social Work, 24(2), 301-308.

Kien, C., Sommer, I., Faustmann, A., Gibson, L., Schneider, M., Krczal, E., Jank, R., Klerings, I., Szelag, M., Kerschner, B., Brattström, P. \& Gartlehner, G. (2019). Prevalence of mental disorders in young refugees and asylum seekers in European Countries: a systematic review. European Child \& Adolescent Psychiatry, 28, 1295-1310.

Kirmayer, L. J., Lemelson, R., \& Barad, M. (Eds.) (2007). Understanding trauma: Integrating biological, clinical and cultural perspectives. New York, NY: Cambridge University Press.

Kouider, E. B., Koglin, U., \& Petermann, F. (2014). Emotional and behavioral problems in migrant children and adolescents in Europe: A systematic review. European Child and Adolescent Psychiatry, 23, 373-391.

Leyendecker, B., Cabrera, N., Lembcke, H., Willard, J., Kohl, K., \& Spiegler, O. (2018). Parenting in a new land: Immigrant parents and the positive development of their children and youth. European Psychologist, 23(1), 57-71. 
LimeSurvey Project Team/Carsten Schmitz (2012). LimeSurvey: An Open Source survey tool. Hamburg, Germany. Retrieved on December $31^{\text {st }} 2020$ from http://limesurvey.org.

Lukaschek, K., Kruse, J., Emeny, R. T., Lacruz, M. E., von Eisenhart Rothe, A., \& Ladwig, K. (2013). Lifetime traumatic experiences and their impact on PTSD: A general population study. Social Psychiatry and Psychiatric Epidemiology, 48(4), 525-32.

Magalhães, S., de, S., Miranda, D. K., de Paula, J. J., de Miranda, D. M., Romano-Silva, M. A., \& Malloy-Diniz, L. F. (2018). Psychometric properties of a Brazilian portuguese version of the children's revised impact of event scale (CRIES-8). Revista de Psiquiatria Clinica, 45(2), 27-32.

McDonald, A., Buswell, M., Khush, S., \& Brophy, M. (2017). Invisible wounds: the impact of six years of war on the mental health of Syria's children. London: Save the Children UK.

McLellan, J. (2015). Religious responses to bereavement, grief, and loss among refugees. Journal of Loss and Trauma, 20(2), 131-138.

Mels, C., Derluyn, I., Broekaert, E., \& Rosseel, Y. (2010). The psychological impact of forced displacement and related risk factors on Eastern Congolese adolescents affected by war. Journal of Child Psychology and Psychiatry, 51(10), 1096-1104.

Miller, A., Hess, J. M., Bybee, D., \& Goodkind, J. R. (2018). Understanding the mental health consequences of family separation for refugees: Implications for policy and practice. American Journal of Orthopsychiatry, 88(1), 26-37.

Miller, K. E., \& Rasmussen, A. (2017). The mental health of civilians displaced by armed conflict: An ecological model of refugee distress. Epidemiology and Psychiatric Sciences, 26, 129-138.

Nunnally, J. C., \& Bernstein, I. H. (1994). The Assessment of Reliability. Psychometric Theory, 3, 248-292.

Oxman-Martinez, J., Rummens, A. J., Moreau, J., Choi, Y. R., Beiser, M., Ogilvie, L., \& Armstrong, R. (2012). Perceived ethnic discrimination and social exclusion: Newcomer immigrant children in Canada. American Journal of Orthopsychiatry, 82(3), 376-388.

Pacione, L., Measham, T., \& Rousseau, C. (2013). Refugee children: Mental health and effective interventions. Current Psychiatry Reports, 15, 315-341.

Papazian-Zohrabian, G., Mamprin, C., Turpin-Samson, A., \& Lemire, V. (2020). Collaborative mental health care for refugee families in a school. In: L. De Haene \& C. Rousseau (Eds.), Working with refugee families: Trauma and exile in family relationships. Cambridge: Cambridge University Press.

Peltonen, K., Qouta, S., Sarraj, E., \& Punamäki, R. L. (2010). Military trauma and social development: The moderating and mediating roles of peer and sibling relations in mental health. International Journal of Behavioral Development, 34(6), 554-563.

Perreira, K. M., \& Ornelas, I. (2013). Painful passages: Traumatic experiences and post-Traumatic stress among US immigrant Latino adolescents and their primary caregivers. The International Migration Review, 47(4), 976-1005.

Perrin, S., Meiser-Stedman, R., \& Smith, P. (2005). The Children's Revised Impact of Event Scale (CRIES): Validity as a screening instrument for PTSD. Behavioural and Cognitive Psychotherapy, 33(4), 487-498.

Persyn, M. K. (2016). Agents of progress: Schools and child traumatic stress. Poverty \& Race, 25(4), 16-22.

Pieloch, K. A., McCullough, M. B., \& Marks, A. K. (2016). Resilience of children with refugee statuses: A research review. Canadian Psychology/Psychologie Canadienne, 57(4), 330-339.

Putnick, D. L., \& Bornstein, M. H. (2016). Measurement invariance conventions and reporting: The state of the art and future directions for psychological research. Developmental Review, 41, 71-90.

Reed, R. V., Fazel, M., Jones, L., Panter-Brick, C., \& Stein, A. (2012). Mental health of displaced and refugee children resettled in lowincome and middle-income countries: risk and protective factors. The Lancet, 379(9812), 250-265.
Rosseel, Y. (2012). Lavaan: An R package for structural equation modeling. Journal of Statistical Software, 48(2), 1-36.

Rousseau, C., Benoit, M., Gauthier, M., Lacroix, L., Alain, N., Viger Rojas, M., \& Bourassa, D. (2007). Classroom drama therapy program for immigrant and refugee adolescents: A pilot study. Clinical Child Psychology and Psychiatry, 12, 451-465.

Rousseau, C. (2020). Interrogating legality and legitimacy in the postmigratory context: Working around traumatic repetition and reenactment with refugee families. In L. De Haene \& C. Rousseau (Eds.), Working with refugee families: Trauma and exile in family relationships. Cambridge: Cambridge University Press.

Rubin, D.E. (1987). Multiple imputation for nonresponse in surveys. New York: Wiley.

Salari, R., Malekian, C., Linck, L., \& Sarkadi, A. (2016). Using CRIES-8 to screen for post-traumatic stress disorder in unaccompanied refugee minors. European Journal of Public Health, 26(1), 8-9.

Salari, R., Malekian, C., Linck, L., Kristiansson, R., \& Sarkadi, A. (2017). Screening for PTSD symptoms in unaccompanied refugee minors: a test of the CRIES-8 questionnaire in routine care. Scandinavian Journal of Public Health, 45(6), 605-611.

Schachner, M. K., Juang, L., Moffitt, U., \& van de Vijver, F. J. R. (2018). Schools as acculturative and developmental contexts for youth of immigrant and refugee background. European Psychologist, 23(1), 44-56.

Schreiber, J. B., Nora, A., Stage, F. K., Barlow, E. A., \& King, J. (2006). Reporting structural equation modeling and confirmatory factor analysis: A review. Journal of Educational Research, 99, 323-338.

Shakya, Y. B., Khanlou, N., \& Gonsalves, T. (2010). Determinants of mental health for newcomer youth: Policy and service implications. Canadian Issues, 98-102. Retreived from: https://accessa lliance.ca/wpcontent/uploads/2018/06/Determinants_of_Mental_ Health_for_Newcomer_YouthCdn_Issues.pdf.

Silove, D., Sinnerbrink, I., Field, A., Manicavasagar, V., \& Steel, Z. (1997). Anxiety, depression and PTSD in asylum-seekers: Associations with pre-migration trauma and post-migration stressors. British Journal of Psychiatry, 170(4), 351-357.

da Silva Rebelo, M. J., Fernández, M., \& Achotegui, J. (2018). Mistrust, anger, and hostility in refugees, asylum seekers, and immigrants: A systematic review. Canadian Psychology/Psychologie Canadienne, 59(3), 239-251.

de Smet, S., Rousseau, C., Stalpaert, C., \& De Haene, L. (2020). I look at you and see you looking at me": Role boundaries in a dynamic research relationship in qualitative health research with refugees. Qualitative Health Research, 30(7), 1083-1100.

de Smet, S., Rousseau, C., Deruddere, N., Kevers, R., Spaas, C., Missotten, L., Stalpaert, C., De Haene, L. (2021). A contextualized perspective on research participation in collaborative refugee research: A multi-site exploration of relational dynamics in collaborative research. Cultural Diversity and Ethnic Minority Psychology.

Suarez-Orozco, C., Todorova, I. L. G., \& Louie, J. (2002). Making up for lost time: The experience of separation and reunification among immigrant families. Family Process, 41(4), 625-643.

Taylor, S., \& Sidhu, R. K. (2012). Supporting refugee students in schools: What constitutes inclusive education? International Journal of Inclusive Education, 16(1), 39-56.

Tedros, A. G. (2019). Promoting the health of refugees and migrants (Report No. A72/25). World Health Organization.

Thompson, Y. T., Song, H., Shi, D., \& Lui, Z. (2021). It matters: Reference indicator selection in measurement invariance tests. Educational and Psychological Measurement, 81(1), 5-38.

UNHCR, UNICEF, \& International Organisation for Migration. (2019). Access to education for refugee and migrant children in Europe. Geneva: United Nations High Commissioner for Refugees.

UNHCR. (2021). Global Report 2020. Geneva: United Nations High Commissioner for Refugees. 
United Nations (2021). Refugees and Migrants: Definitions. Retrieved on August $23^{\text {rd }} 2021$ from: https://refugeesmigrants. un.org/definitions.

Vandenberg, R. J., \& Morelli, N. A. (2016). A contemporary update on testing for measurement equivalence and invariance. In J. P. Meyer (Ed.), Handbook of Employee Commitment. Cheltenham, United Kingdom: Edward Elgar Publishing Limited.

Vervliet, M., Lammertyn, J., Broekaert, E., \& Derluyn, I. (2014). Longitudinal follow-up of the mental health of unaccompanied refugee minors. European Child \& Adolescent Psychiatry, 23(5), 337-346.

Walker, J., \& Zuberi, D. (2020). School-aged Syrian refugees resettling in Canada: Mitigating the effect of pre-migration trauma and post-migration discrimination on academic achievement and psychological well-being. Journal of International Migration and Integration, 21(2), 397-411.

World Health Organization (2014). Adolescence: A period needing special attention. Health for the World's adolescents report. Geneva: World Health Organization. Retrieved on August $23^{\text {rd }} 2021$ from https://apps.who.int/adolescent/second-deca de/section2/page1/recognizing-adolescence.html.

Wright, B., Garside, M., Allgar, V., Hodkinson, R., \& Thorpe, H. (2020). A large population-based study of the mental health and wellbeing of children and young people in the North of England. Clinical Child Psychology and Psychiatry, 25(4), 877-890.

Youth in mind (2018). SDQ: Information for researchers and professionals about the Strengths \& Difficulties Questionnaires. Retrieved on December 30th 2020 from https://www.sdqinfo. com/py/sdqinfo/c0.py.

Caroline Spaas is a doctoral researcher at KU Leuven, Faculty of Psychology and Educational Sciences. Her research focuses on relational processes of post-trauma reconstruction in communitybased care for refugee children, adolescents and their families.

An Verelst is a post-doctoral researcher at Ghent University in Belgium, Faculty of Psychology and Educational Sciences. Her major research interests include the psychosocial impact of armed conflict, terrorism, migration, sexual violence and its implications for policy and care.

Ines Devlieger is a post-doctoral researcher at Ghent University in Belgium, Faculty of Psychology and Educational Sciences. Her major research interests include data-analysis.

Sanni Aalto is a clinical psychologist and doctoral student at Tampere University. Her major research interests include psychosocial interventions promoting migrant well-being and integration.

Arnfinn J. Andersen is a sociologist and is research director at the Norwegian Centre for Violence and Traumatic Stress Studies. His research interests include integration, participation, family, gender, marginalization, migration and health and minorities.

Natalie Durbeej is a researcher at Uppsala University. Her major research interests include early assessment and detection of mental health problems in children and youth, as well as preventive interventions to promote mental health in these populations.

Per Kristian Hilden is a medical anthropologist and senior researcher at the Norwegian Centre for Violence and Traumatic Stress Studies. His major research interests include migration and health, health equity and social justice, marginalization and global health.

Reeta Kankaanpää is a doctoral researcher at Tampere University. Her major research interests include psychological and social assessment and psychometric evaluation.

Nina Langer Primdahl is a research assistant at the University of Copenhagen. Her primary research interests include marginalization, minority health and community-based research methods.

Marianne Opaas is a clinical psychologist and researcher the Norwegian Centre for Violence and Traumatic Stress Studies. Her major research interests include refugees, trauma and psychological treatment.

Fatumo Osman is a nurse and researcher at Uppsala and Dalarna University, School of Education, Health and Social Studies. Her research focuses on implementing and evaluating culturally tailored interventions to promote the mental health of refugee and migrant families.

Kirsi Peltonen is a senior researcher at the University of Turku, Finland, Research Centre for Child Psychiatry. Her major research interests include child mental health, in particular the effect of trauma exposure on children, and psychosocial interventions.

Anna Sarkadi is Professor in social medicine and research leader at Child Health and Parenting (CHAP) research group at the Department of Public Health and Caring Sciences at Uppsala University. The research group CHAP is an interdisciplinary research environment 
focusing on societal interventions to promote the mental health of children and parents.

Morten Skovdal is Associate Professor in Health Psychology at the University of Copenhagen. His research focuses on the contextual factors and relational processes that shape engagement with health services, and promote psychosocial well-being and care in the community.

Signe Smith Jervelund is Associate Professor at the Department of Public Health, University of Copenhagen. Her major research interests include social and ethnic inequalities in access to healthcare services and interventions promoting vulnerable groups' health and integration.

Emma Soye is a doctoral researcher at the University of Sussex. Her research focuses on the contextual factors influencing the social inclusion of migrant and refugee youth.

Charles Watters is Professor of Well-being and Social Care at the School of Education and Social Work, University of Sussex. His major research interests include migration, health, and social care, with a particular focus on the well-being of refugee children.

Ilse Derluyn is Full Professor at Ghent University, Belgium. Her major research interests include the wellbeing of refugee children, waraffected young people and victims of trafficking.

Hilde Colpin is Full Professor at KU Leuven, Faculty of Psychology and Educational Sciences. She conducts longitudinal and intervention research regarding the effect of the social context on children's and adolescents' social-emotional and academic development.

Lucia De Haene is Associate Professor at the Faculty of Psychology \& Educational Sciences, KU Leuven, where she conducts research on refugee family relationships and clinical intervention for refugee families and communities. As family therapist, she coordinates her team in Transcultural Trauma Care for Refugees at the Faculty Clinical Centre, and leads the development of the child psychiatry daycare unit Paso of the University Psychiatry Hospital (UPC KU Leuven). 